NBER WORKING PAPER SERIES

\title{
CAN PAY REGULATION KILL? PANEL DATA EVIDENCE ON THE EFFECT OF LABOR MARKETS ON HOSPITAL PERFORMANCE
}

\author{
Emma Hall \\ Carol Propper \\ John Van Reenen \\ Working Paper 13776 \\ http://www.nber.org/papers/w13776
NATIONAL BUREAU OF ECONOMIC RESEARCH
1050 Massachusetts Avenue
Cambridge, MA 02138
February 2008

We would like to thank Josh Angrist, David Autor, Tim Besley, Ernie Berndt, Simon Burgess, David Cutler, Bob Elliott, Alan Garber, Amanda Gosling, Larry Katz, Alex Mas, Andrew Oswald, Paul Grout, Doug Staiger and participants in seminars at Bergen, Berkeley, Boston University, CEPR Labor seminar, CHERE UTS, Harvard, Melbourne, NBER Health and Labor Studies Programs, UK Department of Health and Warwick University, for helpful comments. We thank South West Observatory for access to HES data, and Davidson Ho, Andrew Jackson, Rowena Jacobs, Mike Damiani and Katharina Janke for their help with data. Financial support is from the ESRC through the Centre for Economic Performance and CMPO Research Centers. Errors in use of these data are our own. The views expressed herein are those of the author(s) and do not necessarily reflect the views of the National Bureau of Economic Research.

NBER working papers are circulated for discussion and comment purposes. They have not been peerreviewed or been subject to the review by the NBER Board of Directors that accompanies official NBER publications.

(C) 2008 by Emma Hall, Carol Propper, and John Van Reenen. All rights reserved. Short sections of text, not to exceed two paragraphs, may be quoted without explicit permission provided that full credit, including (C) notice, is given to the source. 
Can pay regulation kill? Panel data evidence on the effect of labor markets on hospital performance Emma Hall, Carol Propper, and John Van Reenen

NBER Working Paper No. 13776

February 2008

JEL No. I18,J31,J45

\begin{abstract}
Labor market regulation can have harmful unintended consequences. In many markets, especially for public sector workers, pay is regulated to be the same for individuals across heterogeneous geographical labor markets. We would predict that this will mean labor supply problems and potential falls in the quality of service provision in areas with stronger labor markets. In this paper we exploit panel data from the population of English acute hospitals where pay for medical staff is almost flat across the country. We predict that areas with higher outside wages should suffer from problems of recruiting, retaining and motivating high quality workers and this should harm hospital performance. We construct hospital-level panel data on both quality - as measured by death rates (within hospital deaths within thirty days of emergency admission for acute myocardial infarction, AMI) - and productivity. We present evidence that stronger local labor markets significantly worsen hospital outcomes in terms of quality and productivity. A $10 \%$ increase in the outside wage is associated with a $4 \%$ to $8 \%$ increase in AMI death rates. We find that an important part of this effect operates through hospitals in high outside wage areas having to rely more on temporary "agency staff" as they are unable to increase (regulated) wages in order to attract permanent employees. By contrast, we find no systematic role for an effect of outside wages of performance when we run placebo experiments in 42 other service sectors (including nursing homes) where pay is unregulated.
\end{abstract}

\author{
Emma Hall \\ CMPO \\ University of Bristol \\ Bristol, BS8 1TN \\ United Kingdom \\ Emma.P.Hall@dh.gsi.gov.uk \\ Carol Propper \\ Department of Economics \\ University of Bristol \\ Bristol BS8 1TN \\ United Kingdom \\ carol.propper@bristol.ac.uk
}

John Van Reenen

London School of Economics

Centre for Economic Performance

Houghton Street

London WC2A 2AE

ENGLAND

and NBER

j.vanreenen@1se.ac.uk 
Economists have long warned of the unintended consequences of labor market regulation (e.g. Botero et al, 2004). Many rules rationalized by equity considerations can be harmful both to those that they are meant to help and to consumers. There are many studies of labor quantity restrictions (e.g. hiring and firing costs) and labor price floors (e.g. minimum wages). One common but under-studied form of regulation is centralized wage setting, where pay is mandated to be almost flat over a large geographical area which includes very heterogeneous local labor markets. In the US the pay of postal workers, Federal government employees and some unionized employees are set in this way and this extends to physicians, nurses, high school teachers, etc. in many other countries.

We would expect such regulations for nominal wage equality to have unintended effects on both labor supply and the quality of service provision in areas with strong local labor markets. When the outside wage is high the regulated wage acts as a pay ceiling and we would expect this to cause difficulties in recruitment and retention. Over and above the effects of reduced labor supply of permanent workers, large pay gaps may lead to lower motivation and/or lower quality workers, which in turn should lead to a lower quality of service provision. The main contribution of this paper is to confirm this simple economic intuition and to show that centralized pay regulation has exactly this negative impact on consumers in a very stark setting. Our design uses the centralized pay setting of over a quarter of a million nurses in the UK National Health Service (NHS). Nurses account for over half of the clinical staff in hospitals and their number and quality have been argued to be key inputs into the production of patient care, for example motivating California to mandate nurse to patient ratios in all Californian hospitals from January 2004. We find evidence that the regulation of nurses' pay leads to higher fatality rates after admissions for heart attacks and lower productivity in areas with strong labor markets.

In general, testing the impact of wages on organizational performance is challenging, because in a competitive market wages are equalized for workers of the same skill. Where pay is set by regulation, however, there is a wedge between wages inside and outside the regulated sector, which in principle allows the econometrician to identify the impact of fluctuation in external labor markets on firm outcomes. 
One advantage of our setting is that there is a very rigid national pay setting structure for medical staff and well-measured outcomes of hospital quality. Pay for nurses and physicians in NHS hospitals, which provide almost all hospital care in the UK, is set by a central review body that sets pay scales in which there is limited regional variation. The variation that exists does not fully reflect the wages differentials in the external labor markets in which the staff are employed. Regional pay differences are considerable in the UK (e.g. Bulman, 2002). For example, female white-collar wages in North East England are about 60\% lower than in Inner London and these persist after controlling for human capital characteristics and other factors ${ }^{1}$. We would therefore expect to see differences between inside and outside wages reflected in staffing difficulties that manifest themselves in the lower performance of hospitals operating in high outside wage labor markets ${ }^{2}$.

A second advantage of our design is that patient selection (the concern that observed hospital death rates may partially reflect unobserved patient attributes) is less likely to affect our study than if we used US data. The institutional setting is one where there is almost no choice of hospitals by patients and minimal incentives for hospitals to select patients. Medical care is free at the point of use in the UK. In the period we study neither patients nor their family physicians chose hospitals for the emergency treatment of heart attacks: even for non-emergency care patients had little say over where they went for treatment. Hospitals also had, in contrast to US hospitals, little incentive to select low risk and low cost patients. UK hospitals were not required to publish outcome data (for example their mortality rates) and nor were the costs of an individual patient easily identified as full public insurance meant hospital financial systems were not designed to record costs at the patient level. Nevertheless, we carefully assess the evidence for possible selectivity biases through the use of hospital fixed effects, co-morbidity measures and analysis of business cycle influences.

The data we use is from a panel of all acute hospitals in England. To measure performance we examine one measure of hospital quality - the death rate within thirty

\footnotetext{
${ }^{1}$ As in the United States (e.g. Borjas, 2002) the cross sectional dispersion of UK public sector pay is much lower than in the private sector (e.g. Disney and Gosling, 1998).

${ }^{2}$ There is other evidence that falling UK public sector wages relative to the private sector have led to a decline in the quality of the public sector workforce (Nickell and Quintini, 2002).
} 
days of emergency admission for acute myocardial infarction (AMI) ${ }^{3}$ - and one of productivity (total output per clinical worker). We find evidence that the impact of pay regulation is to generate lower hospital quality and productivity in the areas where labor markets are strong, as measured by higher wages in the outside labor market relative to the wage inside the hospital. This effect is not simply due to fewer staff as the effect of outside wages is present even after controlling for standard labor inputs. Nor is the effect the result of general UK labor market conditions. We run many placebo experiments demonstrating that this "outside wage" effect on performance does not occur in similar sectors that are not subject to centralized pay setting (for example, nursing homes for senior citizens). We also show that hospitals in high outside wage areas have to rely disproportionately on temporary agency staff and this intensive use of agency staff is associated with worse health outcomes. Finally, consistent with basic production theory we find that hospitals with a richer mix of skills (e.g. more physicians and more nurses) also have better hospital outcomes.

Our paper is connected to several other literatures in addition to that on the economic impact of pay regulation. First, as mentioned, labor economists have long been interested in the impact of labor market changes on firm performance. Theories of “efficiency wages”, for example, suggest that improvements in the labor market outside the firm's boundaries could lead to decreased productivity within a firm because there may be more shirking (Shapiro and Stiglitz, 1984), a loss of high quality workers (Weiss, 1980) or perceptions of inequity (e.g. Akerlof, 1982; Mas, 2006). It is difficult to test these ideas in an unregulated labor market. Where pay is set by regulation, however, there is a wedge between inside and outside wages that enables identification of the impact of external labor markets on firm outcomes. So we can effectively use regulation to generate exogenous variation in factor prices ${ }^{4}$.

\footnotetext{
${ }^{3}$ Examples of the use of AMI death rates to proxy hospital quality include Kessler and McClellan (2002), Gaynor (2004) and, for the UK, Propper et al (2004 and forthcoming). The advantages of this measure are discussed below.

${ }^{4}$ Cawley et al (2006) find that higher outside wages are associated with worse health outcomes in US nursing homes. In their paper, the mechanism is that stronger external labor markets lead to higher inside wages and therefore a substitution away from nursing care towards labor saving medical interventions. In our paper, by contrast, we hold inside wages fixed and still identify a negative effect of outside wages. In the US where wages are not regulated, increasing factor prices move hospitals up the labor demand curve rather than the labor supply curve. The positive marginal effects of inside wages we find here are consistent with our interpretation that NHS wages are generally set on the labor supply curve.
} 
Second, our findings on the use of temporary agency staff relates to an emerging line of literature on the causes and consequences of the use of temporary workers ${ }^{5}$. Third, we connect to a large literature in industrial organization on productivity dispersion. We document large differences in performance across hospitals, just as has been observed for firms in other sectors (e.g. Foster, Haltiwanger and Syverson, 2005). We argue that one reason for this heterogeneity in the English context is the effect of regulated wages on outcomes. Fourth, our study relates to the literature on the impact of local economic conditions on health. Such studies focus on how economic conditions affect the demand for health by changing people's wealth or stress levels. For example, in recent work, Ruhm (2006) argues that there are a greater number of heart attacks during upturns in the business cycle ${ }^{6}$. Our paper suggests an alternative mechanism that operates through the supply side. In our model labor market conditions, combined with rigid national pay setting, affect the supply of a key clinical input that, in turn, affects health. Finally, our study relates to the literature that examines the relationship between skills and productivity in the context of hospital production (discussed in Appendix A).

The structure of the paper is as follows. In Section I we discuss the institutional background and the nature of the research design. In Section II we sketch the econometric model that we are estimating and issues surrounding the approach. In Section III we discuss the data and in Section IV offer a preliminary data description. Section $\mathrm{V}$ presents the main econometric results and some robustness tests are discussed in Section VI. Finally, Section VII offers concluding comments.

\section{Institutional background and the research design}

In the UK health care is free at the point of use and is provided through the NHS, a state monopoly provider ${ }^{7}$. Just over 1.2 million workers are employed in the NHS and the wages and conditions of clinical staff are strictly regulated. Since our study examines clinical care in acute hospitals we focus on three main occupational groups: physicians, qualified nurses and health care assistants (essentially unqualified clinical

\footnotetext{
${ }^{5}$ For example see Autor and Houseman (2005) or Houseman et al (2003).

${ }^{6}$ We explore the implications of any association between cyclical upturns and community health below.

${ }^{7}$ There is a small privately funded sector, which specializes in the provision of elective services for which there are long NHS waiting lists.
} 
staff). Exact definitions are given in the data section, but broadly clinical staff account for three-quarters of all hospital employees. In our sample $15 \%$ of clinical staff are physicians, $60 \%$ are nurses and 25\% are health care assistants (see Table 1).

Physicians and nurses' pay is regulated to a precise national scale that has little differentiation over the country, despite a wide variation in regional labor markets. Since 1984 these pay scales have been set by two "National Pay Review Bodies" (NPRBs) known as the Review Body for Nursing Staff, Midwives and Professions Allied to Medicine, and the Review Body for Doctors and Dentists. Each year, the Review Bodies take evidence from the Department of Health, the main labor unions and other interested parties before making a recommendation on changes to the level and structure of pay. The government makes the final decision about whether or not to implement their recommendations (it generally implements them in full). For the health care assistants group there is no Pay Review Body and employers have more discretion over setting pay in response to local conditions.

Under these national scales the same terms and conditions apply across the UK and they allow only minor differences in pay between different areas. Additional allowances are paid to those who work in London and contiguous areas, but these are small relative to the differences in the external labor market. These allowances are up to $11 \%$ higher in the highest cost area of Inner London compared to the low cost areas. The outside wage differential is closer to 60\% (see Appendix B). Beyond these regional allowances hospitals have little scope for aligning the pay of qualified staff to conditions in local labor market conditions. Pay scales are short and offer very little scope for either appointing new hires at different points on the scale, or accelerating workers up to higher grades. The centralized pay setting arrangements do not allow pay to be easily adjusted to address staff shortages in local markets.

From an econometric perspective, this institutional setting is attractive because it enables an examination of the impact of different local wages on hospital outcomes. In most labor markets, changes in equilibrium wages will be the outcome of demand and supply shocks, so identifying their impact on hospital outcomes is difficult as the labor price is endogenous to the unobserved shocks. In the UK case the wage inside the hospital (which we will call the "inside wage") is held broadly fixed as outside 
shocks change skill prices (which we will call the "outside wage”) in the local labor market. There is therefore a wedge between the worker's inside wage and the outside wage. Consequently, variation in the outside wage can be used to analyze the effects of labor markets on performance.

Figure 1 illustrates the case for two local labor markets, "North" and "South" where outside wages are much higher in the South than in the North (generating a shift to the left in the labor supply curve). Given an equal pay rate across geographic areas this will mean a lower level of employment in the South compared to the North.

In principle, the regulated wage could be set above the competitive wage so it acts as a minimum wage and thus employers shed staff. However, in the period studied here there were chronic shortages of nurses and clinical unemployment has been close to zero (e.g. Finlayson et al, 2002). Therefore, it is more likely that the wage is being set below the competitive wage generating excess demand ${ }^{8}$. It is possible, however, that wages are set above the competitive wage in some low outside wage areas in the North and workers in these areas are earning rents (we look at this issue in Section VI).

[Figures 1 and 2 about here]

We consider the consequences of regulating wages for health workers in this way, first analyzing employer responses then worker responses. Turning first to the firm side, employers will try to overcome the regulatory constraint in several ways. First, they could over-promote identical workers to higher grades even if they do not have the requisite skills (so-called "grade drift"). This will help them achieve the desired labor quantity, but at the cost of the lower quality of the over-promoted staff. Empirically, after controlling for grading structure we would still expect to see worse quality in the high outside wage areas. Second, employers could offer various nonpecuniary benefits such as better working conditions in the high wage areas. These

\footnotetext{
${ }^{8}$ In the absence of pay regulation, large local hospitals may have monopsony power so the equilibrium wage will not be at the intersection of the labor demand and supply curve. But so long as the regulated wage lies below the monopsony wage, the constraint will still be binding on some employers and the mechanism we identify will operate.
} 
strategies are limited by clinical unions' power in pushing for homogeneous national conditions and governments have been reluctant to challenge this ${ }^{9}$.

Third, assuming the regulated wage is binding, cost-minimizing employers will try to adjust by substituting towards other factors of production. Consequently, other types of staff whose pay is less constrained by regulated pay will increase and non-labor factors will be in higher demand. Because of the specific skills required for different medical interventions, however, substitution to much less skilled workers (health care assistants and non-clinical NHS staff) will be limited. One key group of workers where substitution is easier is temporary "agency" staff. There are a large number of nurses (and other staff) employed in hospitals on temporary contracts. Private sector firms supply temporary agency nurses to the NHS and these workers do not have their pay regulated by the state. Consequently, the availability of agency staff will enable NHS employers to bring their employment closer to their desired levels.

This is illustrated in Figure 2 where we consider a high outside wage labor market ("South”). The regulated wage determines the number of "permanent" staff that the hospital can employ. If the supply of agency nurses is competitive then the wage paid to agency nurses will be bid up to the point that labor demand intersects with labor supply at the competitive wage ${ }^{10}$.

Turning to the employee side, in local areas where outside opportunities are better nurses will supply less labor as shown in Figure 1. In a static sense, this may lead to lower participation rates, as fewer qualified staff will offer themselves for work. In a dynamic search setting this will lead to higher rates of vacancies and turnover in the high outside wage areas.

\footnotetext{
${ }^{9}$ The desire for nominal wage equality across workers in different geographical areas has long been a mainstay of union activity. It is not obvious why this should be the case, as real wages within the NHS are made more unequal since the cost of living varies by area. However, if unions represent the view of the median worker, as in the model of Grossman (1983), this worker may be better off with a more compressed wage policy.

${ }^{10}$ This raises the question of why nurses want to work in the public sector instead of simply becoming agency nurses and earning more. Permanent employees have other non-pecuniary benefits such as greater job security, better promotion prospects and enhanced pensions and heterogeneous preferences over these elements of the job package. Furthermore, there may be stigma attached to being an agency nurse rather than a full-time employee as many nurses are "motivated agents" in the sense of Besley and Ghatak (2005). Nurses could also work in the private sector. However, the demand for nurses in the private sector is limited by the small size of this sector in England and nurses in this sector have less opportunity for promotion and training.
} 
Our focus in this paper is whether there are effects of wage regulation on hospital outcomes over and above the pure effects of reduced labor supply of permanent workers. We focus on nurses as the labor market for physicians is basically a national one, as the NHS operates a career track for physicians that ends with a lifetime appointment to a single NHS hospital, but is preceded by movement between hospitals and regions in a national context, which reflects the national provision of training facilities for physicians.

From the framework above, a stronger local labor market generates substitution towards temporary agency nurses. The reliance on temporary agency workers in the high outside wage areas may reduce hospital performance for several reasons. First, agency nurses may have lower human capital than permanent nurses. Some studies show that they tend to be younger, less experienced and have less training (e.g. Audit Commission, 2001). Second, even for ex ante identical nurses, being a temporary worker may lead to lower productivity in hospitals because of lower job specific human capital ${ }^{11}$. Thirdly, they may also be less committed to the public service "mission" of the NHS (e.g. Besley and Ghatak, 2005). On top of the use of agency staff, there may also be effects of the outside wage on the effort of workers through various efficiency wage channels such as lower motivation and greater shirking.

If mobility were costless and there existed a single national labor market then using local outside wages as a signal of labor market pressure makes little sense. However, mobility in Britain is far less than in the US (for example, less than 1\% of adults move between the UK regions in a given year, compared to 7\% across the much larger US states). Nurses are predominantly female, often with childcare responsibilities and need to be geographically close to hospitals, as they are required to work shifts (Shields, 2004). It is likely, therefore, that mobility is not perfectly responsive to wage differentials. We show some evidence for this below - if mobility was costless it

\footnotetext{
${ }^{11}$ The Audit Commission (2001) finds that agency nurses have little notice before working their shifts and that they are often employed to provide cover at weekends and at night when direct supervision is less likely to be available. As a result, induction and handover may be inadequate, agency nurses may have little time to get accustomed to the workings of the hospital, may be unfamiliar with the patients under their care or with local procedures, practices and equipment, with their surroundings and their colleagues. The Commission argues all these factors increase the chances of poorer quality care.
} 
is unlikely that geographic differentials of the magnitude we observe could be sustained.

\section{Empirical strategy}

\section{A. Modeling Approach}

To motivate our empirical work, assume that we can characterize the output of a representative hospital by a Cobb-Douglas production function ${ }^{12}$

$$
Y=A L^{\alpha} K^{\beta}
$$

where $Y$ is quality constant output, $L$ is effective labor input allowing for quality and quantity dimensions, $K$ is a vector of non-labor inputs (which for expositional simplicity we will treat as scalar) and $A$ is a Hicks neutral efficiency parameter. We denote $L$ as the product of "effort" $(E)$ and labor quantity $(\tilde{L})$, so $L=\tilde{L} E$. Effort is a catch all term for the other factors that transforms labor into efficiency units.

We consider disaggregating the labor quantity into different types of heterogeneous workers so that the labor quantity index can be written as:

$$
\tilde{L}=\sum_{k} \gamma_{k} N_{k}
$$

where $N_{\mathrm{k}}$ is labor of skill type $k$ with relative marginal productivity $\gamma_{k}(>1)$ and we normalize $\gamma=1$ for $k=0$, the lowest skill type ${ }^{13}$. Taking logs of equation (1) and substituting in equation (2) and the definition of $L$, we obtain:

$$
\ln Y=\ln E+\ln A+\alpha \ln N+\beta \ln K+\alpha \ln \left\{1+\sum_{k, k \neq 0}\left(\gamma_{k}-1\right) S_{k}\right\}
$$

where $N$ is the sum of employees and the share of workers of skill class $k$ is $S_{k}=\frac{N_{k}}{N}$. We model the effort function as ${ }^{14}$ :

\footnotetext{
12 This should be viewed as a first-order approximation to a more flexible functional form. It is straightforward to generalize this to more complex functional forms such as translog and we discuss some experiments in the results section.

${ }^{13}$ See inter alia Hellerstein, Neumark and Troske (1999).

${ }^{14}$ See Machin and Manning (1992) for an example of this approach in the efficiency wage literature.
} 


$$
E=e\left(W, W^{O}, Z\right)
$$

Where $W$ is the "inside" wage (i.e. the wage paid inside the hospital), $W^{O}$ is the “outside” wage and $Z$ are other factors affecting effort/quality of workers. We expect effort to be rising in the inside wage and falling in the outside wage other things equal. Using a first order log linear approximation for the effort function, e(.) in equation (4) and substituting this into equation (3) gives:

$$
\ln Y=\ln A+\alpha \ln N+\beta \ln K+\alpha \ln \left\{1+\sum_{k, k \neq 0}\left(\gamma_{k}-1\right) S_{k}\right\}+\delta \ln W+\varphi \ln W^{O}+\ln Z^{\prime} \theta
$$

An alternative to estimating (5) directly by nonlinear least squares is by using the approximation $\ln (1+x) \approx x$ which gives us:

$$
\ln Y=\ln A+\alpha \ln N+\beta \ln K+\alpha \sum_{k, k \neq 0}\left(\gamma_{k}-1\right) S_{k}+\delta \ln W+\varphi \ln W^{O}+\ln Z^{\prime} \theta
$$

Theoretically, the object of the left hand side of equation (6), $Y$, is quality-adjusted output. However, we do not observe this directly. Instead, use two proxies, one of quality and one of total output, as measures of performance. The precise data definitions are discussed below.

\section{B. Interpreting the wage effects}

The wage effects in equation (6) reflect any impact wages may have on (average) worker effort or worker quality. We expect $\varphi<0$ because conditional on a given inside wage $(W)$ an increase in the outside wage $\left(W^{O}\right)$ should reduce effort, $E$. Similarly, holding labor inputs fixed, an increase in the inside wage should increase output $(\delta>0)$. The various mechanisms have been extensively discussed in the efficiency wage literature discussed in the introduction such as shirking, turnover, worker quality and fairness. In the context of the publicly run NHS this may be reflected in a greater reliance on agency nurses, who are contracted on a temporary basis to NHS hospitals. We explicitly examine this and other mechanisms in the results section. 
As discussed above, wages can also have an effect on hospital performance through the quantity of employees of different skill types. Conditioning the production function on labor inputs in equation (6) abstracts away from these effects so we can focus on whether there is an impact of the labor markets through the $E\left(\right.$.) function ${ }^{15}$. We will therefore be underestimating the importance of wages on hospital production and show specifications where we relax this.

\section{Econometric models}

We estimate the "production function" for hospital $i$ at time $t$ as:

$$
\ln (Y / N)_{i t}=\ln A_{i t}+\mu \ln N_{i t}+\beta_{1} S_{i t}^{P H Y S}+\beta_{2} S_{i t}^{N U R S E S}+\delta \ln W_{i t}+\varphi \ln W_{i t}^{O}+\ln Z_{i t}^{\prime} \theta
$$

$Y$ is total output (essentially admissions), $S_{i t}^{\text {PHYS }}$ is the share of physicians in total

clinical staff and $S_{i t}^{\text {NURSES }}$ is the share of qualified nurses (precise definition of all the variables are in Section IV below.) Compared to equation (6) we have used three main skill groups, physicians, qualified nurses and the base category of health care assistants which includes the unqualified nursing staff. Physicians receive the largest amount of training ${ }^{16}$, nurses the second highest amount and health care assistants the least. So in terms of the model we expect $\beta_{1}>\beta_{2}>0$. Note that we have transformed the dependent variable from output into "productivity" so $\mu=\alpha-1$ is a scale parameter that will be equal to zero under constant returns. Our baseline regressions include employment as a control for hospital size, but we also show the robustness to imposing constant returns to avoid an obvious division bias (employment being on the left hand side and right hand side of the regression). We have absorbed the non-labor inputs into the $Z$-vector. Another important set of controls in $Z$ are casemix terms to allow for patients of different severity of illness.

\footnotetext{
${ }^{15}$ Because we observe a discrete number of skill groups one concern is that we are grouping over heterogeneous skill groups within these categories. The interpretation of the inside wage becomes ambiguous because it may simply reflect unobserved labor quality. The coefficient on the outside wage, however, should be robust to this problem of interpretation as the theory implies that it should take a negative value. If outside wages simply proxied for the measurement error in human capital inside the hospital we would expect the coefficient on outside wages to be positive.

${ }^{16}$ Physicians in the UK follow a five year undergraduate Batchelor's program and then spend a further four to eleven years in training, depending on their specialty. Nurses follow a three year undergraduate Batchelor's program to become a registered nurse. Specialist nurses then train for a further year (or more).
} 
Since we have panel data we decompose the unobserved total factor productivity term into its variance components: $\ln A_{i t}=\eta_{i}+\tau_{t}+v_{i t}$ where $\eta_{i}$ is a hospital effect, $\tau_{t}$ are a set of time dummies and $v_{i t}$ is a stochastic error term whose properties we discuss below.

$\ln (Y / N)_{i t}=\ln A_{i t}+\mu \ln N_{i t}+\beta_{1} S_{i t}^{P H Y S}+\beta_{2} S_{i t}^{N U R S E S}+\delta \ln W_{i t}+\varphi \ln W_{i t}^{O}+\ln Z_{i t}^{\prime} \theta+\eta_{i}+\tau_{t}+v_{i t}$

We present results treating $\eta_{i}$ as a fixed effect (e.g. long-differenced results or Blundell and Bond's (1998) system GMM method described below) and also results treating $\eta_{i}$ as uncorrelated with the right hand side variables (i.e. standard OLS). We use various proxies for the outside wage $\left(\ln W_{i t}^{O}\right)$ based on average wages in the local labor market around the hospital. We primarily use measures at a disaggregated level (we have seventy-eight distinct "travel to work" areas in our data), but experiment with a relatively aggregate level (the ten regions of England). We focus on female non-manual wages as this is the most likely comparator group for nurses but we also consider other comparison groups for the outside wage (e.g. male wages). The nature of the NHS means physicians essentially operate in a national labor market: the time dummies will capture their outside wages. Since hospitals are a small part of the local labor market we treat the outside wage as exogenous, although we lag the variable by a year to avoid any immediate feedback effects from transient area level shocks (permanent shocks are picked up by hospital fixed effects).

Identification of the coefficient on the inside wage, $\delta$, is more challenging. We observe the hospital inside wage, but higher wages may reflect a better skill mix such as a superior grading structure, which we do not perfectly observe. Thus, finding a positive coefficient on the average inside wage could simply reflect the better performance of hospitals with higher average human capital. Note, however, that if the outside wage partly reflects higher wages/skills inside the hospital, this will bias the coefficient on the outside wage towards zero, making it harder to reject the null hypothesis. Consequently, we present a first set of results that do not condition on inside wage information under the assumption that the inside wage is truly national. 
We then consider alternative methods of including the inside wage. Our main method is to include the inside wage and use the system GMM approach discussed below to allow for endogeneity.

Identifying the coefficients on the factor inputs in production functions is an old problem in econometrics (see Ackerberg et al, 2007, for a recent survey). In equation (8) the endogenous factor inputs are the numbers of employees of different skill types. Our preferred method draws on a recent contribution by Bond and Söderbom (2005) which examines the estimation of a model of a Cobb Douglas production function when inputs with differential adjustment costs are optimally chosen. In our context we make the plausible assumption that the hospital faces larger adjustment costs from changing the number of physicians relative to adjusting the number of nurses. Under reasonable parameterizations of the adjustment cost process lags of the endogenous variables will be correlated with current values and this can be used to justify the moment conditions underlying the Blundell and Bond (1998) estimator as applied in the production function context (e.g. Blundell and Bond, 2000). Essentially this estimator builds on the traditional moment conditions that lagged levels of the endogenous variables can be used to instrument the first differenced endogenous variables (Arellano and Bond, 1991). By (testable) assumptions on the initial conditions the system GMM approach also allows lagged differences to be used as instruments for the equation in levels. The approach allows the current employment of all skill groups to be affected by shocks to productivity (i.e. endogenous in the production function). We compare the GMM approach to alternative methods of estimating equation (8) by long differences and by OLS in levels.

The hospital quality equation is estimated in a symmetric way to the production function. Our measure of quality is death rates following admission for emergency heart attacks (AMI) by individuals 55 years and over (the reasons for the choice of this variable is discussed below). All the coefficients are allowed to differ as indicated by the " $\mathrm{D}$ " superscript:

$$
\ln D_{i t}=\mu^{D} \ln N_{i t}+\beta_{1}^{D} S_{i t}^{\text {PHYS }}+\beta_{2}^{D} S_{i t}^{N U R S E S}+\delta^{D} \ln W_{i t}+\varphi^{D} \ln W_{i t}^{O}+\ln Z_{i t}^{\prime} \theta^{D}+\eta_{i}^{D}+\tau_{t}^{D}+v_{i t}^{D}
$$

The $Z$ vector includes AMI specific controls for case-mix. 


\section{Placebo experiments on other industries}

A concern with interpreting the coefficient on the outside wage as the effects of regulation is that there may be other unobservables correlated with both hospital performance and the outside wage. A test of this is to conduct a placebo experiment and estimate the model in other industries where pay is not regulated. If the outside wage also had a significant effect on firm performance in these sectors we would conclude that regulation was not generating our results in the hospital sector.

We conduct one placebo experiment on nursing homes for elderly people. This sector employs many nurses whose wages are not regulated by the Pay Review Bodies, so it seems a good comparator. We also estimated firm panel models of productivity separately for 42 separate service industries, most of which have a large proportion of female workers. These were all the three-digit 1987 US Standard Industrial Classification codes 53 through 60 and 71 through 81 (we excluded only the public sector and the predominantly male construction sector).

\section{E. Selection Issues}

A concern with equation (9) is that there may be unobservable patient characteristics correlated with the outside wage that make it more likely for AMI death rates to be higher. Although this could in principle be a problem, we argue that our research design and robustness tests indicate that selection is not contaminating our results.

\section{(i) Research Design}

We argued in the Introduction that our research design makes selection much less than it would in a study on US data. The key outcome is in-hospital death rates from emergency admissions. Incentives for patients to select hospitals were minimal or non-existent in the time period we study. Treatment is free at the point of use so quality is the only dimension patients would make a choice on. But there was almost no public information on hospital quality until after $2001^{17}$, so during the period we study patients (and their doctors and buyers of health care) had almost no quality information on which to choose hospitals. Further, patient choice was not encouraged.

\footnotetext{
${ }^{17}$ There were no published indicators of quality available until 1999, when six were published. More were made available from 2001.
} 
There is no private sector hospital care for emergency AMI in the UK. Finally, patients having heart attacks are not in a position to make a choice of hospital (Volpp et al 2003).

Any incentives to select will therefore come from the hospital side. But during this period, incentives for hospitals to choose patients were also weak. As there was no data on quality, hospitals were not monitored on their clinical performance. So on performance grounds they had little incentive to refuse potentially sicker patients. Hospitals were not paid per patient, but received a block budget for emergency care. So in theory they had greater financial incentives to turn away high cost patients than in a system where reimbursement rates are (at least to some extent) adjusted for severity (for example the US DRG arrangements). However, the fact that hospitals were not paid per patient and all treatment was (and remains) free meant that the financial systems in NHS hospitals were not set up to identify high cost patients ${ }^{18}$. We conclude that, in practice, incentives for hospitals to select or to engage in differential treatment of sicker patients were very weak in the period we study.

\section{(ii) Controls for patient quality}

Although we believe our research design makes selection issues less of a concern, it does not eliminate them. To tackle the problem we introduce a large number of controls for patient co-morbidity. First, we include in all regressions controls for casemix such as the age and gender composition of emergency AMI admissions in a particular hospital in a particular year. Second, we condition on mortality rates in the local area which should pick up other unobservable influences on death rates from ill health. Third, we present estimates controlling for unobservable hospital fixed effects. Finally, in robustness checks we also condition on information on the severity of the AMI admissions.

\footnotetext{
${ }^{18}$ There are large fixed costs with introducing such a patient monitoring system and, in the absence of strong incentives, hospitals did not use them. As evidence of this, when a cost per patient reimbursement system was introduced in England three years after the end of our data in 2004, two years had to be allowed between its introduction and full roll-out.
} 


\section{(iii) Business cycle effects on demand for health}

Recently it has been suggested that population heart attack fatalities are positively correlated with the business cycle. For example, Ruhm (2006) argues that there is a greater number of heart attacks during "good times" using US state level unemployment rates. It is therefore possible that the impact of high outside wages that we find is not due to the result of nurse shortages within hospitals, but to increases in fatalities due to the business cycle. While possible, there are several reasons why our results seem unlikely to be driven by the effect of the business cycle on population health. First, the group which appears to suffer most from falls in unemployment during cyclical upturns is those aged 20 to 44 . We examine fatalities of persons aged 55 and over. Second, any relationship between business cycles and population health is likely to be affected by institutions (Ruhm 2006, Gerdtham and Ruhm 2002). The UK has a stronger welfare state and higher levels of labor protection relative to the US. These may limit the mechanisms by which it is hypothesized that upswings translate into heart attack fatalities. One mechanism is the impact of increased hours and reduced leisure, which it is argued leads to less investment in health production by younger workers and less time to care for older persons. Hours are significantly less associated with the cycle in the UK than the US (Gali 2005). So there may be less cyclicality of health investment (we present evidence that this is the case below) ${ }^{19}$. We also examine conditioning on health related aspects of the local business cycle such as pollution.

We therefore consider it unlikely that a positive association between high outside wages and heart attack fatalities in the population outside the hospital drives our results. However, as noted above, we use time varying controls for local population health to control for any impact of the cycle on the health of those admitted to hospitals. We also undertake an extensive series of robustness checks to attempt to establish that a negative relationship between wages and population health is not the source of our results.

\footnotetext{
${ }^{19}$ The indirect caring effect is also likely to be mitigated by the UK social care system that provides subsidized care for older persons and acts as a substitute for care from relatives.
} 
(iv) Selection prior to hospital arrival or after hospital exit

Data constraints mean that we do not observe deaths prior to being admitted to hospital nor after thirty days in hospital or after leaving the hospital. Lack of data post discharge is unlikely to be problem as we discuss in detail in Appendix B. In short, 98\% of AMI deaths occur within thirty days of being admitted to hospital; in fact over half of deaths are within the first 48 hours.

The time between heart attack and hospital arrival ("Floor to door") is in principle important. But in our sample period ambulance staff provided little health care for AMI victims. For example, even as late as 2000 only $0.6 \%$ of AMI emergencies received reperfusion (treatment to stop clotting) from ambulance staff prior to arrival at hospital (Birkenhead, 2005). Additionally, we show in the results section there was no relationship between the outside wage and time spent in the ambulance (due to, say, congestion on the roads).

\section{Data}

We have built an original, very rich database with "plant-level” panel information on hospital quality, productivity and inputs such as staff skills and patient case mix. This was compiled from a large number of mainly administrative data sources that we discuss briefly here and in more detail in Appendix B and Tables A1-A3.

\section{A. Basic information}

The unit of observation in this study is the hospital, so all measures are at hospital level. We construct a panel data set of NHS hospitals (called "trusts" in the UK ${ }^{20}$ ) covering the financial years $1995 / 6$ to $2002 / 3$. The panel is unbalanced as the number of hospitals changes over the period. In 1995 the number of acute hospitals in our data was 234, and fell to 175 in 2002 . We focus only on acute hospitals ${ }^{21}$.

\footnotetext{
${ }^{20}$ An NHS “trust” is a financial, managerial and administrative unit and may cover more than one physical hospital. It is appropriate to think of a hospital as a firm that may be single plant or multiplant. We use the term "hospital" rather than "hospital trust" for expositional convenience.

${ }^{21}$ Non-acute hospitals are a more heterogeneous set (they include mental health and community hospitals) and generally do not provide emergency AMI treatment.
} 


\section{B. Measures of quality, productivity and casemix}

These are derived from hospital episode statistics (HES) data. We measure quality of output by within hospital deaths within thirty days of admission for emergency acute myocardial infarction (AMI) for patients aged 55 or over. AMI was chosen for several reasons. First, it is a common condition and the infrastructure used to treat AMI is common to other hospital services making it a good general marker of hospital quality $^{22}$. Second, all patients with a recognized AMI are admitted, so there is little scope for selection bias to affect the decision of who gets admitted (see the previous section). Third, the quality of hospital care has been established to have an important effect on survival rates, so there is ample scope for hospitals to affect outcomes (Volpp et al, 2003). As an indication, deaths following emergency admission for AMI have been published by both US and UK governments as indicators of hospital quality. McClellan and Staiger (2000) argue that measures of AMI death rate correlate well with other measures of quality. Fourth, variants of this measure have been used widely in studies of hospital quality (starting with Kessler and McClellan, 2000).

We use annual hospital-level averages and, to avoid the problem of variability of rates from small denominators, we only undertake analyses using hospitals with at least 150 emergency AMI admissions per year (results are robust to changes in this threshold).

To allow for differences in case-mix we include three sets of controls. First, we control for unobserved hospital fixed effects, which will control for differences in case-mix that are constant over time. Second, we control for all-cause time-varying mortality of the catchment area of the hospital ${ }^{23}$ and will pick up the degree of ill health of the population that the hospital draws its cases from. Third, we control for the age-gender distribution of admissions for emergency AMI: the proportion of emergency AMI admissions in five year bands separately for men and women. Fourth, in robustness tests we control for more detailed AMI case-mix measures based on the severity of the heart attack. Of course, there may remain some time varying, within area, unobservable that increases AMI death rates that are not captured by area

\footnotetext{
${ }^{22}$ Many of the actions to reduce deaths from emergency admissions for AMI need to be taken soon after an attack, and so the performance of a hospital in terms of AMI reflects the performance of its accident and emergency department. Around half the patients admitted to an acute English hospital are admitted through the accident and emergency department.

${ }^{23}$ Constructed from data on 354 Local authorities and standardized for age and gender.
} 
mortality rates or the other observables. However, this unobservable would have to be systematically positively correlated with outside wages in order to bias our results.

Productivity is measured in a way similar to labor productivity in studies of other sectors, as total output per worker. Our measure of total output is finished consultant episodes (FCEs). This is a standard output measure used in the NHS and indicates the total volume of medical activity (e.g. Vita 1990). To allow for variation in case mix, we again control for hospital fixed effects and for the age-gender profile of total admissions at hospital level and type of admission ${ }^{24}$. In robustness tests we include further controls for the case-mix of total admissions using an index based on the costs of the procedures and diagnoses of all inpatient admissions.

\section{Wages}

We use several measures of outside wages. Our main measure is derived from the New Earnings Survey (NES), which is a one per cent sample of all employees in Great Britain covering about 300,000 individuals a year. The NES is mandatory administrative panel data provided by firms to the Department of Work and Pensions and contains information on earnings and hours. Our main measure is average annual earnings, but we also consider hourly wages. We use the area code in the NES to construct seventy-eight distinct county-based travel to work areas (or boroughs in London). Using the zipcodes ("postcodes”) of the headquarters of county councils, we matched each NHS hospital to all county councils that fell within a twenty-kilometer radius from the hospital. The local area wage is constructed as the average of the county wages of all the councils that fell into this radius. Where no councils fell within the twenty kilometer radius the wage applicable to the nearest council was used $^{25}$.

Our main measure is the average wages of non-manual female workers since the overwhelming bulk of nurses are women ${ }^{26}$. The nature of the NHS means physicians’

\footnotetext{
${ }^{24}$ The proportion of admissions in eighteen five-year age bands for males and females separately plus the proportion of admissions in three categories: emergencies, electives, transfers (omitted category is elective).

${ }^{25}$ About one quarter of trusts had no council within a twenty kilometer (thirteen mile) radius. Almost half of the trusts had only one council within a twenty kilometre radius from the trust, with the remaining quarter having two or more councils.

${ }^{26}$ As an alternative to the NES we also considered the Labor Force Survey (LFS). The LFS is a selfreported household survey containing about 320,000 individuals per year (with 80,000 observations on wages). From the LFS we can extract spatial wage differentials conditioning on more characteristics to
} 
labor markets are national in scope and so local outside wages will be less important for this group. Our main measure of the inside wage is simply the average wage paid to clinical workers in the hospital, derived from staff numbers and expenditure data ${ }^{27}$.

\section{Skill Groups}

We define three clinical skill groups: physicians, qualified nurses (including qualified Allied Healthcare Professionals, AHPS, such as radiologists and physiotherapists), and health care assistants (including unqualified nurses and allied health professionals). Extensive checks show that our results are not sensitive to the summation over the qualified and unqualified. The staff measures are annual whole time equivalents. We define total clinical staffing as the sum of staffing across these groups. Shares for each group of staff are defined relative to this measure ${ }^{28}$.

\section{Preliminary data description}

Table 1 presents the means, standard deviations, minimum and maximum for the variables used in the regression analysis for our sample of hospitals. On average, $21.1 \%$ of emergency heart attack admissions die within thirty days with a wide range from as few as $7 \%$ to as many as $37 \%$. The average acute hospital is large with just under 1,700 clinical workers.

\footnotetext{
build up the outside wage offered to a "typical” nurse. We experimented with such measures that successfully predict labor supply problems in the cross section (e.g. Elliot et al, 2007). The smaller sample size and sampling variation, however, means that such constructed variables are less useful in a panel data analysis. So for the most part, we rely on the larger sample sizes of the NES that has less measurement error as it is taken directly from employer records. We also experimented with using measures of unemployment rates and employment rates as alternative indicators of labor market "tightness". We did not find that these added explanatory power over and above the information in the wage, which in principle should fully reflect labor market conditions.

${ }^{27}$ A problem with a measure of average wages is that it may reflect the skill mix, such as differential grades within the hospital (as discussed above in the econometric section). We therefore also experimented with a more exogenous measure of the price of labor based on the predicted regional wage for a nurse following the method of Gosling and Van Reenen (2006). We use mandated wage uprating by the National Pay Review Body (which has an area and grade specific component) to calculate the predicted wage increase for an average nurse in the trust using the regional characteristics based on the NES. The results are similar to those reported here and are available on request.

${ }^{28}$ We also have a total employment measure that includes the non-clinical staff, but this does not disaggregate between highly skilled groups such as senior managers and less skilled groups such as janitors. Consequently, our main results use total clinical staff as the main employment measure and we check the robustness of the results to conditioning on the total employment measure (see Table 6).
} 


\section{A. Variation of AMI rate and productivity over time}

Figure 3 presents the distribution of AMI deaths between 1995 and 2002. We show the $10^{\text {th }}, 25^{\text {th }}, 50^{\text {th }}, 75^{\text {th }}$ and $90^{\text {th }}$ quantiles of the distribution. The most striking feature of Figure 3 is the remarkable variation of death rates at any point in time between different hospitals. For example in 1995 the death rate is s17\% for the bottom decile and $27 \%$ in the top decile. Some of this variation can be accounted for by case mix but there remains much residual variation that is potentially related to the quantity and quality of labor inputs. Looking at the evolution of the distribution, Figure 3 shows a gradual decrease in death rate over time indicating the long run trend in a decline in the emergency AMI death rate. There is some convergence in death rates between hospitals at the top and bottom of the distribution towards the end of the period. This convergence and the falls in 2002 follow a major government initiative to reduce the incidence of coronary heart disease through the "National Service Framework"29. Although this is a genuine feature of the data we dropped 2002 to avoid any contamination of the main results because of this major policy initiative ${ }^{30}$.

[Figures 3 and 4 about here]

Figure 4 illustrates the distribution of productivity which shows a large dispersion some $60 \%$ between the top and bottom deciles in 1995 . This heterogeneity mirrors the well-known findings in the productivity literature that has looked at differences between private sector firms: there is significant and persistent variation in productivity even within disaggregated sectors that cannot be explained by observable factor inputs. The figure also shows clearly the lack of a positive trend in our measure of productivity.

\section{B. Outside wages and outcomes: vacancies, labor supply and AMI death rates}

In Figure 5 we display the geographical variation in outside wages, the intensity of use of temporary agency nurses and AMI death rates to see if the raw data suggest the relationships we have been discussing. There is considerable spatial variation in all three measures. The similarity in patterns between the distribution of outside wages and intensity of agency nurses is particularly striking, being concentrated heavily in

\footnotetext{
${ }^{29}$ The framework set new standards and protocols, backed by increased resources and incentives. See http://www.rcplondon.ac.uk/pubs/books/minap/HowHospitalsManageHeartAttacks12Nov2002.pdf. After 2001 there were also other reforms to improve NHS performance, which included tougher targets for waiting times in Emergency Rooms (see Friedman and Kelman, 2006, for an analysis).

${ }^{30}$ The results are stronger if we include this year.
} 
London and other urban centers with stronger labor markets. The pattern in AMI deaths is slightly different, reflecting amongst other things, the distribution of population ill-health which is higher in areas of greater poverty such as the North East. Nevertheless there is considerable overlap in the regional distribution of AMI deaths and that of outside wages and use of agency staff.

[Figure 5 about here]

We now examine some simple correlations across regions. First we plot the mean outside wage against the nurse vacancy rate in Figure 6 across the ten English regions. A clear upward sloping pattern emerges with the highest outside wage area (London) having a vacancy rate that is fourfold higher than the vacancy rate in the lowest outside wage area (the North East). Gosling and Van Reenen (2005) discuss the correlation between nurse labor supply measured as the proportion of women with a nursing qualification who are employed as nurses (rather than being employed in another occupation or not participating). They show that labor supply is much lower in the regions where outside wages are higher. In Inner London, for example, nurse wages are about 5\% lower than the regional average outside wage, whereas in the North East of England nurses' wages are 30\% higher than the outside wage. In London the nurse participation is $50 \%$ and in the North East participation rates are $75 \%{ }^{31}$.

[Figures 6 and 7 about here]

Figure 7 examines the intensity of using agency nurses and the outside wage. Again, we find that the regions with high outside wages rely a lot more on agency nurses than the regions with low outside wages. Figure 8 plots the AMI death rate as a function of the regional outside wage. There appears to be a positive relationship, London having the highest AMI death rates and the low-outside wage regions of the North having lower AMI death rates. In Figure 9 we consider these variables in growth rates over the five-year period in our sample. Again, it appears that there is a positive relationship between the change in the outside wage and the growth rate of AMI. Although all areas have had some improvement in the quality of hospitals as

\footnotetext{
${ }^{31}$ It cannot be concluded from this simple comparison that nurses outside London are earning quasirents from the public sector so that the regulated wage is above the unregulated wage in Figure 1. This is because the comparison does not take into account non-pecuniary aspects of being a nurse, which may be an unattractive occupation for many people. These non-pecuniary aspects are likely to be relatively stable over time, however, so econometrically we control for them with fixed effects.
} 
measured by AMI death rates, the rate of improvement was fastest in those regions with the slowest increase in outside wages.

[Figures 8 and 9 about here]

Overall then, regions with high outside wages are characterized by higher vacancy rates, greater use of temporary agency staff and higher death rates from $\mathrm{AMI}^{32}$. There are, of course, many reasons why these figures may be misleading and there is no causal connection between high outside wages and poor hospital performance. For example, there may be many other factors positively influencing the outside wage and the AMI death that we have not controlled for. To tackle this we turn to the econometric results where we look at within region variation both in the cross section (by using area and hospital trust level data) and in the time series (by controlling for hospital fixed effects) as well as conditioning on confounding variables such as casemix and local mortality rates.

\section{Main results}

In this section we present our main results looking at the effect of outside wages on hospital quality and productivity. We then consider including inside wages, the magnitudes of the effects, and the role of agency nurses, our placebo tests and other robustness results.

\section{A. Hospital quality as measured by death rates from AMI}

Table 2 presents the estimates for hospital quality as measured by the log of the AMI death rate. The outside wage is that derived from the log of the average wage of nonmanual women in the seventy-eight local "travel to work" areas. Column (1) presents the pooled OLS estimates of the association of AMI death rates with staff shares and outside wages, controlling for AMI casemix (admissions in fourteen age-gender bands), hospital type (i.e. whether the hospital was a normal acute hospital or a

\footnotetext{
${ }^{32}$ These results fit with Gosling and Van Reenen (2005), who use a long panel of regions between 1984 and 2001 (when there were some significant changes in mandated regional differences) to find a 10\% fall in nurse relative wages reduces nurse employment by up to 15\%. Elliott et al (2007) find a positive cross sectional relationship between vacancies and high outside wages.
} 
teaching hospital), the local area mortality rates, hospital size (the log of total clinical employees), year dummies and ten regional dummies ${ }^{33}$.

Column (1) of Table 2 confirms that the bivariate correlation in Figures 8 and 9, which showed that higher outside wages are associated with higher AMI death rates ${ }^{34}$, remains robust after adding controls. A 10\% increase in outside pay is associated with a 4\% increase in AMI death rates. It also reveals that hospitals with better qualified employees (i.e. a higher proportion of physicians and/or qualified nurses relative to health care assistants) have lower AMI death rates. The coefficients are sensible being larger for physician share (the highest human capital group) compared to nurse share. Nevertheless, even after controlling for skill mix, the outside wage enters the regression with a significantly positive sign.

Note that the standard errors are clustered by hospital. An alternative is to cluster by area, but the standard errors were extremely close to those presented here, due to the large number of areas ${ }^{35}$.

Column (2) of Table 2 considers long-differenced specifications (annualized three year differences) ${ }^{36}$. The patterns of signs on the key variables are the same as OLS in levels, but less precisely determined. The coefficient on the outside wage is positive and significant at the 5\% level. The skill share variables are correctly signed but smaller in magnitude ${ }^{37}$. Finally, column (3) contains our preferred system GMM

\footnotetext{
${ }^{33}$ The results were robust to including other measures of hospital size as extra controls (e.g. number of finished consultant episodes, total number of beds or the total admissions). These terms were never significantly different from zero.

${ }^{34}$ Note that we also considered other health quality outcomes that showed similar patterns to those reported here for AMI. For example, if we use death from strokes as the dependent variable in an equivalent specification to column (1) the coefficient on outside pay is 0.475 with a standard error of 0.191 . The coefficient on physician share was -2.305 with a standard error of 0.513 .

${ }^{35}$ The area-level clustered standard error on the outside wage in column (1) of Table 2 was 0.170 (as compared to 0.176 when we cluster by firm). For productivity, the area-level clustered standard error on the outside wage in column (1) of Table 3 was 0.199 (as compared to 0.198) when we cluster by firm. See Bertrand et al (2004) or Cameron et al (2007) for a recent discussion of these issues.

${ }^{36}$ We focus on long-differences to reduce the attenuation bias associated with transitory measurement error. Including a full set of hospital dummies (within groups) leads to similar marginal effects with larger standard errors. For example the coefficient on the outside wage in an identical specification to column (1) estimated by within groups is 0.433 with a standard error of 0.324 .

${ }^{37}$ Running the regressions using five year differences also lead to strong results: the coefficient on the outside wage was 1.718 with a standard error of 0.707 . Note that the casemix variables were jointly insignificant in the long-differences specifications so we do not include them ( $p$-value of joint significance is 0.353 ).
} 
specification that treats skill shares and total employment as endogenous. This estimator exploits the "within" information used in columns (2) and the levels information used in column (1). The marginal effect of the outside wage is statistically significant and similar in magnitude to column (1). The coefficients on the skill shares are significant and larger in absolute magnitude compared to the previous columns. This suggests some endogeneity bias of the coefficients on skill shares, possibly because hospitals with high AMI rates rely on skilled staff to a greater extent, which biases the OLS coefficients on the skill shares towards zero.

The diagnostics are given at the base of Table 2. For the instrumental variables to be valid for system GMM there should be no second order serial correlation in the differenced residuals and no correlation of the error term with the instruments. The high p-values on the $\operatorname{LM}(2)$ and Sargan test are consistent with the validity of the instrument set $^{38}$.

\section{B. Hospital Productivity}

Table 3 repeats the analysis on the same sample as Table 2 but uses productivity as the dependent variable. The order of the specifications is identical to Table 2 and the control variables are the same except we use the vector of case mix controls specific to total admissions. Column (1) shows that the share of physicians is significantly and positively associated with higher productivity, while the share of nurses is also positive, but statistically insignificant. Most importantly, higher outside pay is associated with significantly lower productivity. A $10 \%$ increase in outside pay is associated with a $6.6 \%$ decrease in productivity.

The long-differenced results are much weaker with no variable significant, possibly reflecting the low degree of within-hospital variation in productivity. The final column of Table 3 presents the preferred GMM results. Here, all three key variables

\footnotetext{
${ }^{38}$ The p-value of the Sargan-Difference test of the invalidity of the extra moment conditions used by the Blundell and Bond estimator (compared to the standard moment condition of Arellano and Bond, 1991 ) is 0.973 . This implies the additional moments are not rejected, justifying the more efficient estimation technique.
} 
are correctly signed and significant. The magnitudes of outside pay and physician share are similar to OLS, but the coefficient on qualified nurse share is larger ${ }^{39}$.

In summary, and taking both tables together, we have two key results. First, a richer skill mix, in particular using more physicians, appears to have a positive association with the quality and quantity of hospital output. This is what basic human capital theory would predict although, to our knowledge, this has not been demonstrated before in the health sector. Secondly, and more interestingly, higher outside wages tend to depress the quality and productivity of hospitals. This is a more controversial finding. In particular, we find that these outside wage effects exist even after conditioning on skill inputs, so the outside wage coefficient is not simply reflecting a lower quantity of key staff. We consider the other mechanisms through which external labor markets may be having an effect on hospital quality and productivity below.

\section{Inside Wages}

According to our model, effort, quality and labor supply are determined by the comparison between the inside wage in the hospital and the outside wage in the labor market. We first have focused on the outside wage because of the relatively small exogenous variation in the inside wage for a comparable nursing grade. In Table 4 we look at this in more detail by re-running all the specifications in Tables 2 and 3 conditioning on the inside wage (the average clinical wage in the hospital).

Column (1) of Table 4 includes the inside wage in the OLS AMI death rate regressions. The marginal effect of inside wages is negative as expected - higher inside wages are associated with a significant reduction in AMI death rates. The coefficient on outside wages remains very similar to Table 2 and remains significant. The coefficients on the skills share terms do fall, however, and they are no longer statistically significant. This suggests that the inside wage reflects, at least partially, the different skill mix within a hospital. Similar results are observed in column (2) for long differences and column (3) for GMM.

\footnotetext{
${ }^{39}$ The Hansen-Sargan test rejects the validity of the instruments in this column. In the next sub-section we show that this is due to misspecification - the omission of inside wages.
} 
The final three columns of Table 4 use productivity as the dependent variable. In contrast to the AMI regressions, the skill share terms dominate the inside wage in the OLS productivity regression of column (4). The strongest evidence is in the GMM results of column (6) where we find a positive and significant coefficient on the inside wage - a $10 \%$ increase in hospital pay is associated with a $2.5 \%$ increase in

productivity. Outside wages remain negative and highly significant, however. The Hansen-Sargan test no longer rejects at the 5\% level suggesting that the main diagnostic problems of Table 3 were related to the omission of inside wages.

Overall, we find some suggestive evidence that inside wages matter for hospital performance, but identifying their effects is much harder than the effect of the outside wage. Nevertheless, the coefficient on the outside wage, our key variable of interest, remains robust to conditioning on the inside wage.

\section{Magnitudes}

The results appear to be statistically significant, but are they economically significant? A $10 \%$ increase in the outside wages (holding the inside wage and labor inputs fixed) is associated with a $4.6 \%$ increase in death rates (Table 2 column (3)). The decile ratio of outside wages between areas in 1996 was about 33\%, so a move from the worst to best decile of labor markets is associated with a $15.2 \%$ increase in death rates. Thus a gap of this size could account for just over one quarter of the $60 \%$ quality spread in the $90-10$. A $10 \%$ increase in outside wages is associated with a $5.5 \%$ fall in productivity (Table 3 column (3)). Moving from the best to worst decile of labor markets is associated with an $18.2 \%$ increase in productivity, which is just under a third of the $60 \%$ between hospital productivity spread.

We can also compare our estimates of the impact of the labor market with those for specific medical interventions for AMIs. Our estimates suggest a $10 \%$ increase in the outside wage is associated with just under a five per cent increase in death rates, which is about a one percentage point increase at the mean death rate of $21 \%$ in our data. Heidenriech and McClellan (2001) estimate that the effect of increasing the use of aspirins in treatment of AMI patients in the US by 70 percentage points (from 5 to 75 percent) was a fall of 3.3 percentage points in death rates; the effect of increasing the use of thrombolytics from 0 to 31 percent was a 1.6 percentage point fall; and the 
effect of increasing use of beta blockers from $21 \%$ to $50 \%$ was a 0.6 percentage point fall. Austin and Mamdami (2006) estimate that prescription of statins at discharge reduced three-year mortality by 2.1 to 4.5 percentage points.

Of course, although these show benefits, the costs of different policy interventions are very different. Back of the envelope calculations (see Appendix C) show that in terms of life-years saved, raising wages is much more costly compared with pharmaceutical interventions. We calculate that there is an implied value of a life-year of $\$ 100,000$ from raising wages compared to the $\$ 50,000-\$ 100,000$ generally used in US costeffectiveness studies (see Skinner et al, 2006) ${ }^{40}$.

Although across the board increases in the level of wages are not cost-effective, changes in the regulation to allow the structure of nurse wages to reflect local labor market conditions are more beneficial. We return to this in the Conclusion.

E. What is the mechanism through which higher outside wages affect hospital outcomes? The role of temporary agency staff

The estimates above show that quality and quantity of hospital output are negatively associated with the outside labor market wage. We have interpreted the coefficient on the outside wage as reflecting worker quality. We now examine whether alternative measures of staff quality are directly associated with outside wages and clinical outcomes. The channel we examine is the possible greater reliance on temporary agency staff in high outside wage areas. If agency staff have lower general or hospital-specific human capital they may depress hospital outcomes ${ }^{41}$.

We have information available to construct a measure of the intensity to which hospitals rely on nursing agency staff for a sub-sample of the data. We use the proportion of total staff costs accounted for by agency nurses as our indicator in Table 5 (“Agency”). The first column reports regressions of this measure of intensity of use of agency nurses on the outside pay rate (and other controls). There is a highly significant correlation, suggesting that agency nurses are more commonly used in the

\footnotetext{
${ }^{40}$ In the UK the National Institute of Clinical Excellence uses a figure of $\$ 60,000$.

${ }^{41}$ In a related literature, several recent papers (e.g. Autor and Houseman, 2005) have suggested that temporary jobs are not "stepping stones" to better careers which is consistent with the notion that workers build up little human capital in these positions.
} 
high outside wage areas. Column (2) then includes the agency term directly in a hospital AMI death rate regression identical to our preferred model (this is column (3) of Table 4$)^{42}$. A greater use of agency staff is associated with significantly higher death rates in hospitals; a doubling of the intensity of use of agency staff is associated with a 5.7\% increase in the death rate. Column (3) simply repeats the preferred specification on the sub-sample with non-missing agency nurse information with only outside wages for comparison purposes. The results are very similar to the larger sample. Then column (4) presents a "horse race" with both agency and outside wage measures entered simultaneously. The outside wage coefficient falls to almost half of its value in the previous column and is no longer significant at even the $10 \%$ level. The coefficient on the agency variable also falls but it remains significant at the $10 \%$ level. This suggests that an important part of the way that the outside labor market is affecting hospital quality is through a greater reliance on temporary agency workers. In support of this finding, detailed analysis of the payroll data of a small number of hospitals indicates that agency staff are disproportionately deployed in emergency rooms (known as accident and emergency departments in the UK), through which emergency AMI cases are admitted. ${ }^{43}$

The next three columns of Table 5 repeat the experiment but use productivity instead of AMI death rates as an outcome measure. In column (5) we show that a greater use of agency staff is associated with significantly lower productivity. Column (6) shows that the marginal effect of the outside wage on productivity is significant in the subsample where we have agency staff information (although somewhat larger in magnitude). In column (7) where we condition on agency intensity the magnitude of the outside wage coefficient falls by about $10 \%$ of its value in the previous column, but remains significant at the $1 \%$ level. The coefficient on agency staffing has fallen by about half but remains significant at the $1 \%$ level $^{44}$.

\footnotetext{
${ }^{42}$ We treat the agency variable as the other endogenous hospital-level variables like physician share and instrument it with past values in the GMM approach.

${ }^{43}$ There are no published breakdowns of where agency staff are deployed within NHS hospitals. Analysis of detailed payroll data of fourteen NHS Trusts (data used in Crilly et al, 2007) shows the share of agency staff expenditure accounted for by Accident and Emergency departments averages 9.1\%. This is around twice the share of total nursing staff spend in Accident and Emergency departments (4.7\%) and is higher than the share of total nursing staff costs accounted for by agency staff $(7.9 \%)$.

${ }^{44}$ We also re-estimated Table 5 by OLS and GMM excluding the inside wage and the results are similar.
} 
To further explore the role of agency staff, we examine whether there is a link between agency staffing and a specific adverse medical outcome that is a major problem in UK hospitals. Since 2001 acute NHS hospitals in England have been subject to mandatory reporting of Methicillin-resistant Staphylococcus aureus bacteraemias (bloodstream infections) ${ }^{45}$. This is known in the media as the MRSA “Superbug”. It has been argued that hospital acquired infections are associated with hospital physical cleanliness. For the UK, it has been hypothesized that greater reliance on agency nurses may be associated with higher rates of MRSA. Temporary nurses may be less knowledgeable about local infection control policies, and move around more between wards within hospitals as well as switching between hospitals. This implies a greater number of patient contacts per agency nurse, and patients on wards with higher numbers of temporary staff may come into contact with more staff, since temporary workers often work shorter shifts than permanent workers.

MRSA data is only available for 2001 and 2002. For these years we regressed MRSA rates against agency staff intensity controlling for the same variables as in Table 2 column (1). Consistent with McCormick et al (2007) we found a positive and significant association between levels of MRSA rates and use of agency staff (a coefficient of 0.015 with a robust standard error of 0.006 ).

Taken as a whole, these results are suggestive that agency staffing may be part of the mechanism through which higher outside wages negatively affect hospital outcomes.

\section{F. Placebo Tests: No role for the outside wage in other sectors}

A concern with our results is that the effects of the outside wage may be due to some other factor than pay regulation. If this were so we would also expect outside wages to affect performance in other sectors that had similar characteristics to hospitals. In this section we conduct several placebo experiments to show that our outside wage measure is not systematically correlated with performance in these sectors. We look at one sector in depth and then consider 42 other private sector service industries.

\footnotetext{
${ }^{45}$ Stapylococcus Aureas (SA) are bacteria commonly carried on the skin and it is estimated around $30 \%$ of the population of the UK carries SA bacteria at any one time. SA bacteria can cause serious infections such as surgical wound infections and pneumonia. Bacteraemia infections occur when the MRSA enters a normally sterile bloodstream either through an intravenous catheter or a local site of infection.
} 
We first consider nursing homes for senior citizens. Health care workers are employed intensively in this sector which provides both medical and "hospitality" services for elderly people on a long-term basis. Unlike hospitals, however, firms are free to set wages without being constrained by a centralized regulated nursing wage. Firm-level panel data for 1998 and 1999 was collected for 649 randomly selected nursing homes which included extensive characteristics ${ }^{46}$. One measure of labor productivity specific to this sector is the number of occupied beds per hour worked. This does not take into account the differential quality of nursing homes, so our baseline results use revenues per hour - this weights raw productivity figure by the price charged to stay in the home (under the assumption that the higher quality nursing homes are more expensive). We compare this with the beds per hour measure as well.

Table 6 contains the results. The key variable of interest is exactly the same as in the earlier tables; the outside wage in the local labor market. We also control for the average wage in the home (the inside wage), the proportion of employees who have nursing qualifications, overall firm size (employment), gender composition, average worker age, the proportion of residents subsidized by the government, regional dummies and year dummies. In column (1) we report the basic results that show that the inside wage is positive and significant (which could represent either unobserved skills or efficiency wages). More importantly, the outside wage term although negative is completely insignificant. Column (2) includes average hours as an additional control since wages may affect hours worked (the denominator of the dependent variable). The coefficient on the outside wage remains insignificant and actually becomes positive. In 1999 the UK introduced a national minimum wage so this constrained firms to pay a legal minimum. To make sure that this is not contaminating our results we re-estimate on the 1998 cross section only in column (3) and again the outside wage is insignificant ${ }^{47}$. In column (4) we include a full set of firm fixed effects. Although the inside wage remains positive and significant the outside wage remains insignificant. Finally, in column (5) we use output per hour

\footnotetext{
46 See Appendix B and Machin and Wilson (2004) for a more detailed data description

${ }^{47}$ We also constructed the wage "gap" - the proportion that the 1998 wage bill in the home would have to increase in order to comply with the minimum wage law. This is highly correlated with subsequent wage growth. The outside wage term remains insignificant when the "gap" is included as an additional variable.
} 
instead of revenue per hour as the dependent variable without changing the qualitative results.

We also examined production functions from a number of other service industries where there were many female employees. In contrast to the US, all UK firms are legally required to lodge their accounts in Companies' House and, if they are above a minimum size threshold, legally obliged to report their wage bill, employment, sales and other characteristics (even if they are not listed on the Stock market). This data is available electronically through BVD’s Amadeus Dataset (see Appendix B for details) and we exploit this to run panel data regressions of labor productivity (ln(revenues per worker)) on the outside wage. We mimic the same three specifications of Table 3 (OLS, long-differences and system GMM) including as additional controls the inside wage, $\ln ($ employment), the $\ln ($ capital-labor ratio), regional and year dummies. The full results for these 126 regressions (three specifications in forty-two industries) are summarized in Appendix Table A4. In only seven cases was the coefficient on the outside wage negative and significant at the $5 \%$ level $(5.6 \%$ of the total number of regressions), which is what would be expected by pure chance given the large number of regressions.

Taken together, these results from sectors where there are no maximum pay limits suggests that the negative effect of outside wages is limited to the hospital sector. The absence of such a placebo effect in the other industries strongly suggests that it is regulation which is causing the results rather than some other unobserved factor.

\section{Robustness of the results}

We describe here a sample of the large number of robustness checks we performed on the main results. These are summarized in Table 7. All cells report the coefficient and standard error on the outside wage from separate regressions. The first column has AMI death rates as the dependent variable and the second column has productivity as the dependent variable. Both columns include the inside wage. We begin in row 1 with a baseline regression taken from Table 4 columns (3) and (6). The other regressions use this as the baseline in the rest of the table. 


\section{A. Severity of AMI cases and the local labor market}

As discussed above, Ruhm (2006) has suggested that a booming local labor market could increase ill health and the incidence of heart attacks and has presented US evidence to support this hypothesis ${ }^{48}$. We have sought to deal with co-morbidity through an extensive set of demographic controls, area mortality rates and hospital fixed effects. But it is possible there are still omitted casemix variables and that a positive correlation between economic activity and severity of patients admitted that is driving our results. We test the robustness of our results to this idea in a number of ways.

First, we examine whether the severity of those admitted with AMI is associated with outside wages. Using HES data we calculated the proportion of emergency AMI cases that were admitted "with complications” compared to the total ${ }^{49}$. Regressing this AMI case severity measure on the outside wage and all the variables in a specification like column (1) of Table 2 shows that there is no significant association with outside wages $^{50}$. We then include this measure of AMI casemix severity directly in the AMI death rate regressions (row 2 of Table 7). In simple OLS specifications - as in Table 2 column (1) - the coefficient on this variable took the expected positive sign and was statistically significant (0.262 with a standard error of 0.116$)$ when we omitted our demographic controls. When the demographic controls were included, the extra comorbidity variable was positive but insignificant (in OLS or in GMM). This suggests that our included demographics are doing a good job at reflecting casemix. The marginal effect of the outside wage was very similar when the extra casemix variable was included as shown in the first column of row 2.

As a robustness check for the productivity regressions we use a casemix variable based on the severity of all admissions to each hospital. This index, known as the reference cost index, is derived from all admissions to the hospital as classified by

\footnotetext{
${ }^{48}$ Note our outcome measure differs from the population AMI rates in Ruhm (2006). Our measure is the death rate conditional on having a heart attack. So Ruhm's effect of strong labor markets causing more heart attacks is distinct from our measure of hospital quality.

${ }^{49}$ We constructed this ratio from the proportion of emergency patients 55 years or older admitted with HRG codes E11 (AMI with complications) and E12 (AMI without complications). For discussion of HRGs, see Appendix B.

50 The coefficient on outside wages was 0.001 with a standard error of 0.041 . If we drop the time dummies, however, the coefficient on the outside wage becomes positive and significant (0.068 with a standard error of 0.030 ), suggesting that it is important to control for omitted aggregate time shocks.
} 
Healthcare Resource Group (HRGs are similar to US DRGs, Diagnostic Related Groups - see Appendix B). A higher value of the index reflects greater complexity of cases. When included in the productivity regressions the relative costs index takes the expected sign and is significant (the index has a coefficient of -0.715 and a standard error of 0.186). The effect of the outside wage is robust, however, remaining negative and significant (row 3 column (2) of Table 7).

Second, we investigate whether outside wages are associated with higher AMI death rates at the community level (i.e. in the whole local area both inside and outside hospitals). We would expect some positive relationship between community level death rates and outside wages as our model implies that local death rates rise because of the decline in hospital quality, even though in-hospital deaths only account for a minority of local area deaths (Norris et al, 1998). The Ruhm hypothesis suggests a strong positive relationship. Taking the local authority as the unit of observation, we examine the relationship between (age and gender standardized) AMI death rates and our outside pay variable (lagged), controlling for year and local authorities effects for 1996-200151. We find, as expected, a small positive relationship, but one which is insignificantly different from zero. The coefficient on outside pay is 0.04 (standard error $=0.17)$.

The lack of any strong positive relationship between outside wages and AMI fatalities at community level is supported by a lack of a positive relationship between outside wages and factors that might drive higher community level fatalities. We found no significant correlation between increases in outside wages and increase in levels of pollution, smoking or obesity, all of which are key risk factors for $\mathrm{AMI}^{52}$.

\footnotetext{
${ }^{51}$ There are 354 local authorities in England. These are the primary political level below national level in England.

${ }^{52}$ Regressing smoking on outside wages using local authority as the unit of analysis with controls for local authority fixed effects and year, we find a coefficient of -0.078 (standard error $=0.120$ ). Regressing obesity on outside wages using local authority as the unit of analysis with controls for local authority fixed effects and year, we find a coefficient of 0.11 (standard error $=0.11$ ). We examined the relationship between four measures of air borne pollutants (carbon monoxide, nitrogen dioxide, particulate matter and ozone) and found no evidence of a positive association between pollution and outside pay. Instead, the evidence points to a negative association.
} 
We conclude that our finding of a positive relationship between in-hospital mortality and outside wages seems unlikely to be driven by an association between outside wages and poorer health in the area from which the hospital draws its patients.

\section{B. Outside labor markets affecting care in ambulance prior to hospital?}

Medics distinguish two important periods after a heart attack: "floor to door" (from having the heart attack to admission to hospital) and "door to needle” (from admission to initial treatment - usually injection of an anti-blood clotting agent such as a thrombolytic drug). Since our measure of quality is death rates from AMI taken from the moment a patient is admitted to hospital, it is possible that the outside wage is actually affecting treatment in the floor to door period. Perhaps the most obvious mechanism would be that stronger economic activity generates more road congestion causing patients to arrive at hospitals later and decreasing their chances of survival. To check this we re-estimated AMI equations including an additional control for ambulance speeds (the proportion of urgent ambulance journey arriving on time). Our outside wages estimates were robust to this control (coefficient of 0.446 with a standard error of 0.172$)^{53}$.

More subtly, hospitals in high outside wage areas may have higher death rates because of the behavior of ambulance crews. If ambulance crews were of poorer quality in high outside wage areas (for the same reason as nurse quality is poorer) then patients might arrive in hospitals in a worse state and therefore be more likely to die in the "door to needle” period. Over our time period, however, there was hardly any treatment of heart attack patients in ambulances. For example, in 2000 only $0.6 \%$ of reperfusion (thrombolytic drugs) for heart attack patients was given before admission to hospital in 2000 and 2001 (Birkenhead, 2005). We conclude that poorer treatment by ambulance crews in high outside wage areas is unlikely to drive our results.

\section{Financial Pressure}

An alternative explanation for the importance of the outside wage is that hospitals in stronger local labor markets face sharper budgetary constraints. The British government's funding formula for the health service contains a "market forces factor" that allocates more funds to reflect the higher costs in more expensive areas, but it

\footnotetext{
${ }^{53}$ These data are only available as a consistent series for three years in our data.
} 
may not fully compensate (e.g. Crilly et al, 2007). Consequently, hospitals in high wage areas may be chronically under-funded and this could cause worse quality and productivity. To test this idea we included a measure of the hospital's financial surplus (or deficit) as an additional control. In row 3 we show that the coefficient on the outside wage remains significant and very similar in magnitude in the sub-sample where we have information on a hospital's financial position.

\section{Dynamics and short-run monopsony}

We were concerned that we may have misspecified the econometric model and not allowed for sufficient dynamics. The specification in row 4 of Table 7 includes a lagged dependent variable (treated as endogenous using the standard GMM approach) and presents the long-run effects of outside wages. Although the lagged dependent variable was significant, the long-run effects of the outside wage remain significant and become slightly larger in absolute magnitude for both equations. The fact that there is a long-run effect of outside wages is important and consistent with the cross sectional raw data in Figures 6 through 8. Labor supply difficulties in the NHS are not simply due to hospitals optimally smoothing their labor force in response to positive

shocks (due to higher adjustment costs for permanent compared to temporary staff) or because of short-run monopsony power as may be the case in the US (see Houseman et al, 2003). They appear to be long-term.

\section{Regional heterogeneity in effect of outside wage}

According to Figure 1, the high outside wage areas may be affected more by the regulated wage than the low cost areas (for example, the regulated wage may be close to the unregulated equilibrium wage for the North). Consequently, we would expect a larger effect in London than in the rest of the country. We experimented with dropping London from the sample in row 5. As we expect, the marginal effects are somewhat smaller in this reduced sample for both AMI and productivity, but they remain significant at the $5 \%$ level.

\section{E. Further Robustness Tests}

We also tried dropping some outliers in the change in the outside wage in row 6 and running the regressions only on the balanced panel in row 7. The results are stronger than the baseline in these sub-samples. In row 8, we use an alternative measure of the 
outside wage - the regional wage in each of the ten English regions (i.e. much more aggregated than the seventy-eight area outside wages used in our main analysis). The marginal effects are larger in magnitude but statistically insignificant unless we drop the regional dummies (row 9). This illustrates the importance of using spatially disaggregated measures. In row 10 we include a variable measuring total hospital employees, including non-clinical workers. The employment variable is insignificant and the coefficient on outside wages falls, but is still significant at the $5 \%$ level.

One simple concern is that the inclusion of linear skill shares in equation (7) may be too restrictive. We relax this by including squares and cross-product terms of the three skill groups in row 11 . The higher order terms were generally insignificant and the coefficients on the outside wage terms remain significant and are larger in absolute magnitude.

Overall then, our results appear robust to a wide variety of experiments.

\section{Conclusions}

This paper has examined the impact of centralized pay regulation on the performance of hospitals. Regulated skill prices offers a useful identification strategy for examining the impact of labor markets on organizational performance relative to a competitive labor market where wages inside and outside the firm should be equalized. Our unusually rich data of a panel of essentially all acute hospitals in England allows us to control for a number of confounding influences.

We find that keeping pay flat over heterogeneous local labor markets leads to lower hospital performance (as indicated by higher AMI death rates and lower productivity) in areas with stronger outside labor markets ${ }^{54}$. This is not simply because hospitals in high outside (relative to inside) wage areas have trouble maintaining high enough staffing levels, as we condition on labor inputs. It is more likely to be due to the difficulty of retaining high quality staff and/or the lower levels of effort that are supplied when outside wages are high. The negative association between firm

\footnotetext{
54 One of the little-discussed costs of centralized wage setting proposed by some macro-economists (e.g. Layard, Nickell and Jackman, 2005) are these types of perverse effects on firm productivity.
} 
performance and the outside wage is unique to hospitals - we do not find it in the other 43 service sectors we examine where their pay is not regulated, such as the market for nursing homes for senior citizens.

We show that reliance on temporary agency staff instead of permanent staff is a possible mechanism in generating these worse outcomes for hospitals in high outside wage areas. This finding is related to the emerging literature on the quality of temporary jobs for workers (e.g. Autor and Houseman, 2005).

One further direction we would like to explore is the impact of regulated prices on technology adoption (see Acemoglu and Finkelstein, 2006). Our setting is useful because the external regulation of wages enables us to examine whether part of the performance effect comes from the adoption of sub-optimal techniques. We have collected data on the management practices and organizational structure of these hospitals (using the methodology of Bloom and Van Reenen, 2007) in order to understand in more detail the mechanisms generating the extreme variation we observe in hospital performance.

From a policy perspective, our study has important implications for regulated labor markets. The National Health Service, a quasi-monopoly provider, dominates the UK health system and wages for physicians and nurses are determined centrally. The local variation of wages does not fully reflect the higher outside wage in areas where the labor market is tight (such as London and the South East). The low relative wages in these high outside wage areas appear to have a direct impact on the death rates in hospitals and the level of their productivity. Rather than focusing on across the board increases in national pay which we found not to be cost effective, relaxing the regulatory system to allow local wages to reflect local market realities would improve productivity and save lives in the higher outside wage areas. 


\section{References}

Acemoglu, Daron and Finkelstein, Amy. 2006. "Input and Technological choices in regulated industries: Evidence from the healthcare sector” MIT mimeo

Ackerberg, Daniel, Lanier Benkard, Steven Berry, and Ariel Pakes. 2007. "Econometric Tools for Analyzing Market Outcomes.” Handbook of Econometrics Volume VI, edited by James Heckman, and Ed Leamer.

Aiken, Linda H., Sean P. Clarke, Robyn B. Cheung, Douglas M. Sloane, and Jeffrey Silber. 2003. "Educational Levels of Hospital Nurses and Surgical Patient Mortality.” Journal of the American Medical Association 290(24) 1617-1623.

Akerlof, George. 1982. “Labor contracts as Partial Gift Exchange” Quarterly Journal of Economics, 97, 543-569

Antonazzo, Emmanuel, Anthony Scott, Diane Skatun, and Robert F. Elliott. 2003. "The labor market for nursing: a review of the labor supply literature" Health Economics 12 (June): 467-478

Arellano, Manuel and Stephen Bond. 1991. "Some Tests of Specification for Panel Data: Monte Carlo Evidence and an Application to Employment Equations” Review of Economic Studies 58: 277-297.

Audit Commission. 2001. Brief Encounters: getting the best from temporary nursing staff. London: Audit Commission.

Austin, Peter C., and Muhammad M. Mamdani. 2006. “A comparison of propensity score methods: a case-study estimating the effectiveness of post-AMI statin use.” Statistics in Medicine 25 (June): 2084-2106

Autor, David, and Susan Houseman. 2005. “Do Temporary Help Jobs Improve Labor Market Outcomes for Low-Skilled Workers? Evidence from Random Assignments.” MIT mimeograph, Cambridge, MA.

Bertrand, Marianne, Duflo, Esther and Mullainathan. 2004. "How much should we trust difference in difference estimates” Quarterly Journal of Economics, 119, 249-275

Besley, Timothy, and Maitreesh Ghatak. 2005. "Competition and Incentives with Motivated Agents.” American Economic Review 95 (June): 616-636.

Birkenhead, J. S. 2005. "Presentation of data from National Audit of Myocardial Infarction (MINAP)” www.rcplondon.ac.uk/college/ceeu/ceeu_ami_home.htm

Blundell, Richard, and Stephen Bond. 1998. "Initial conditions and moment restrictions in dynamic panel data models.” Journal of Econometrics 87: 115-143.

Blundell, Richard, and Stephen Bond. 2000. "GMM estimation with persistent panel data: an application to production functions.” Econometric Reviews 19 (3): 321340

Bond, Steven, and Måns Söderbom. 2005. "Adjustment costs and the identification of Cobb Douglas production functions.” Institute for Fiscal Studies Working Paper no. W05/04 (February).

Bloom, Nick and Van Reenen, John. 2007. "Measuring and Explaining Management practices across firms and nations." Quarterly Journal of Economics, CXII, (4) 1351- 1408

Borjas, George J. 2002. "The Wage structure and the Sorting of Workers into the Public Sector.” NBER Working Paper no. 9313 (November).

Botero, Juan C., Simeon Djankov, Rafael La Porta, Florencio Lopez-De-Silanes, and Andrei Schleifer. 2004. “The Regulation of Labor.” Quarterly Journal of Economics 119 (November): 1339-1382. 
Bulman, Joanna. 2002 "Patterns of Pay: Results of the 2002 New Earnings Survey.” Labor Market Trends 110 (December): 643-655.

Cameron, Colin, Gelbach, Johan and Miller, Douglas. 2007. "Bootstrap based improvements for inference with clustered standard errors” NBER Technical Working Papers No.344

Cawley, John, David C. Grabowski, and Richard A. Hirth. 2006. "Factor Substitution in Nursing Homes.” Journal of Health Economics 25 (March): 234-247.

Crilly, Tessa, John Crilly, Margaret Controy, Roy Carr-Hill, and David Parkin. 2007. "Review of Specific Cost Approach to Staff Market Forces Factor.” Report to the UK Department of Health (May).

Cutler, David and McClellan, Mark. 2001. "Is Technological Change in Medicine Worth It?” Health Affairs 20: 11-29.

Disney, Richard, and Amanda Gosling. 1998. "Does it pay to work in the public sector?” Fiscal Studies 19 (November): 347-374.

Finlayson, Belinda, Jennifer Dixon, Sandra Meadows, and George Blair. 2002. "Mind the gap: the extent of the NHS nursing shortage.” British Medical Journal 325 (September 7): 538-541.

Frijters, Paul, Michael A. Shields, and Stephen W. Price. 2003. "Investigating the Quitting Decision of Nurses: Panel Data Evidence from the British National Health Service.” IZA Discussion Paper no. 794 (June).

Foster, Lucia, John Haltiwanger, and Chad Syverson. 2005. "Reallocation, Firm Turnover, and Efficiency: Selection on Productivity or Profitability?” NBER Working Paper no. 11555 (August).

Friedman, John and Kelman, Steve. 2006. "Effort as Investment: Analyzing Incentives in the Public Sector”, mimeo, Harvard University

Gali, Jordi. 2005. "Trends in Hours, Balanced Growth and the Role of Technology in the Business cycle” Federal Reserve Bank of St Louis Review, 87 (4), 459-86.

Gaynor, Martin. 2004. "Competition and Quality in Health Care Markets. What Do We Know? What Don't We Know?” Economie Publique 15: 3-40.

Gerdtham, Ulf-G and Ruhm, Christopher, J. 2002. "Deaths Rise in Good Economic Times: Evidence from the OECD”. IZA Discussion Paper No. 654.

Gosling, Amanda and Van Reenen, John. 2006. "Using Institutionalized pay setting to identify the effect of wages on employment: The Case of Nurses.” mimeo, Centre for Economic Performance, London School of Economics.

Grossman, G. 1983. “Union Wages, Seniority and Unemployment” American Economic Review, 73, 277-90

Heidenreich, Paul A. and McClellan, Mark. 2001 "Trends in treatment and outcomes for acute myocardial infarction: 1975-1995.” The American Journal of Medicine 110 (February): 165-174.

Hellerstein, Judith, David Neumark, and Ken Troske. 1999. "Wages, Productivity and Worker Characteristics: Evidence from Plant-Level Production Functions and Wage Equations.” Journal of Labor Economics 17 (July): 409-446.

Houseman, Susan N., Arne L. Kalleberg, and George A. Erickek. 2003. "The Role of Temporary Agency Employment in Tight Labor Markets.” Industrial and Labor Relations Review 57 (October): 105-127.

Kessler, Daniel P. and Mark B. McClellan. 2000. "Is Hospital Competition Socially Wasteful?” Quarterly Journal of Economics 115 (May): 577-615.

Layard, Richard, Nickell, Stephen and Jackman, Richard (2005) Unemployment, Oxford: Oxford University Press, Second Edition 
Machin, Steve and Manning, Alan. 1992. “Testing Dynamic Models of Worker Effort” Journal of Labor Economics, 10(3) 288-305

Machin, Stephen and Wilson, Joan. 2004. "Minimum Wages in a Low Wage Labor Market: Care Homes in the UK”, Economic Journal, 114, 102-109.

Mas, Alex (2006) "Pay, Reference Points and Police Performance" Quarterly Journal of Economics, 121 (3) 783-821.

McCormick, Barry, Ian Stone, and P. Sherrell. 2007. "Hospital Organization, Specialty Mix and MRSA.” mimeo, UK Department of Health.

Nickell, Stephen, and Glenda Quintini. 2002. "The Consequences of the Decline in Public Sector Pay in Britain: A Little Bit of Evidence.” Economic Journal 112 (February): F107-F118.

Norris, R M on behalf of the United Kingdom Heart Attack Study Collaborative Group (1998) "Fatality outside hospital from acute coronary events in three British health districts 1994-5” British Medical Journal, 316, pp 1065-70.

Office of Manpower Economics. 2003. Workforce Survey results for Nursing Staff, Midwives and Health Visitors. London: Office of Manpower Economics.

Propper, Carol, Simon Burgess, and Denise Gossage. (2007). "Competition and Quality in Hospital Markets: Evidence from the NHS Internal Market 199199.” Economic Journal, forthcoming.

Propper, Carol, Simon Burgess, and Katharine Green. 2004. "Does Competition between hospitals improve the quality of care? Hospital death rates and the NHS internal market.” Journal of Public Economics 88 (July): 1247-1272.

Review Body for Nursing Staff, Midwives, Health Visitors and Professions Allied to Medicine. 2003. Twentieth report on nursing staff, midwives, health visitors and professions allied to medicine 2003. London: Stationery Office.

Ruhm, Christopher. 2006. “A Healthy Economy Can Break Your Heart.” NBER Working Paper no. 12102 (March).

Shapiro, Carl, and Joseph Stiglitz. 1984. "Equilibrium Unemployment as a Worker Discipline Device.” American Economic Review 74 (June): 433-44.

Skinner, Jonathan S, Staiger, Douglas O, and Elliott S Fisher. 2006. "Is Technological Change in Medicine Always Worth It? The Case of Acute Myocardial Infarction.” Health Affairs 25 (February): w34-w47.

Shields, M., (2004), Addressing Nurse Shortages: What can Policy Makers Learn from the Econometric Evidence on Nurse Labor Supply? Economic Journal, 114 : 464-498.

Vita, Michael G. 1990. "Exploring hospital production relationships with flexible functional forms.” Journal of Health Economics 9: 1-21.

Volpp, Kevin, Sankey V. Williams, Joel Waldfogel, Jeffrey H. Silber, J. Sanford Schwartz, and Mark V. Pauly. 2003. "Market Reform in New Jersey and the Effect on Mortality from Acute Myocardial Infarction.” Health Services Research 38 (April): 515-533.

Weiss, Andrew (1980) "Job Queues and layoffs in Labor Markets with Flexible Wages”, Journal of Political Economy, 88, 526-38 
Table 1: Descriptive statistics

\begin{tabular}{|c|c|c|c|c|}
\hline & Mean & $\begin{array}{l}\text { Standard } \\
\text { deviation }\end{array}$ & Min & Max \\
\hline \multicolumn{5}{|l|}{ AMI Variables } \\
\hline AMI death rate (55 plus) & 21.14 & 4.483 & 7.454 & 36.941 \\
\hline Total AMI deaths (55 plus) & 79.99 & 33.83 & 13 & 294 \\
\hline Total AMI admissions (55 plus) & 385.02 & 160.84 & 151 & 1,348 \\
\hline \multicolumn{5}{|l|}{$\begin{array}{l}\text { Productivity and FCE (finished } \\
\text { Consultant Episodes) }\end{array}$} \\
\hline $\begin{array}{l}\text { Productivity (total FCEs/ total } \\
\text { clinical staffing) }\end{array}$ & 31.17 & 7.57 & 12.09 & 65.12 \\
\hline Total FCEs & $58,664.58$ & $24,515.83$ & 13,490 & 138,984 \\
\hline \multicolumn{5}{|l|}{ Staffing Variables } \\
\hline $\begin{array}{l}\text { Total clinical staffing (physicians } \\
+ \text { nurses + Allied Health }\end{array}$ & 1675.79 & 692.25 & 398.61 & 4010.70 \\
\hline \multicolumn{5}{|l|}{ Professionals + Health Care } \\
\hline $\begin{array}{l}\text { Physicians share of clinical } \\
\text { staffing }\end{array}$ & 0.148 & 0.030 & 0.058 & 0.270 \\
\hline $\begin{array}{l}\text { Qualified Nurses (plus qualified } \\
\text { Allied Health Professionals) share }\end{array}$ & 0.597 & 0.037 & 0.476 & 0.741 \\
\hline Health Care Assistants share & 0.246 & 0.046 & 0.121 & 0.393 \\
\hline \multicolumn{5}{|l|}{ Hospital Expenditure Variables } \\
\hline $\begin{array}{l}\text { Share of expenditure on agency } \\
\text { staff as a proportion of total } \\
\text { expenditure ("Agency”) }\end{array}$ & 0.034 & 0.028 & 0.001 & 0.163 \\
\hline $\begin{array}{l}\text { Retained Surplus (£1000);745 obs } \\
\text { Wages }\end{array}$ & -206.1 & 1313.4 & -11487 & 8505 \\
\hline Ln(Area outside wage) & 9.60 & 0.140 & 9.27 & 9.99 \\
\hline Ln(nurse inside wage) & 9.99 & 0.152 & 9.52 & 10.50 \\
\hline Ln(area inside wage) & 10.09 & 0.110 & 9.53 & 10.45 \\
\hline \multicolumn{5}{|l|}{ Other variables } \\
\hline $\begin{array}{l}\text { Directly Standardized Mortality } \\
\text { rate in local area (per } 100,000 \text { ) }\end{array}$ & 723.43 & 77.13 & 518.73 & 944.21 \\
\hline Teaching trust & 0.111 & 0.341 & 0 & 1 \\
\hline $\begin{array}{l}\text { Proportion of emergency } \\
\text { admissions (to total admissions) }\end{array}$ & 0.411 & 0.082 & 0.224 & 0.808 \\
\hline $\begin{array}{l}\text { Proportion of transfer admissions } \\
\text { (to total admissions) }\end{array}$ & 0.160 & 0.066 & 0 & 0.448 \\
\hline $\begin{array}{l}\text { Proportion of AMI admissions } \\
\text { with complications (HRG E11) }\end{array}$ & 0.162 & 0.075 & 0 & 0.667 \\
\hline HRG case mix index; 892 obs & 93.98 & 9.08 & 75.49 & 175.89 \\
\hline MRSA rate; 216 obs & 0.169 & 0.088 & 0.02 & 0.55 \\
\hline
\end{tabular}

Notes: Acute hospitals in 211 English NHS (regression sample used in Tables 2-4). Unless otherwise noted, data are for 901 observations between 1996 and 2001. Other case mix variables are admissions within 5 year age-gender bands for emergency AMI (age 55+) and for total admissions. Staffing variables refer to whole time equivalent clinical staffing. 
Table 2: Hospital quality and the outside wage

\begin{tabular}{llll}
\hline $\begin{array}{l}\text { Dependent variable } \\
\text { Estimation technique }\end{array}$ & $\begin{array}{l}\text { Ln(AMI Death Rate) } \\
\text { OLS } \\
(1)\end{array}$ & $\begin{array}{l}\text { Ln(AMI Death Rate) } \\
\text { 3 year annual Long Differences } \\
(2)\end{array}$ & $\begin{array}{l}\text { Ln(AMI Death Rate) } \\
\text { GMM-SYS } \\
(3)\end{array}$ \\
\hline & $0.407^{* *}$ & $0.766^{* *}$ & $0.460^{* * *}$ \\
Ln (Area outside wage) & $(0.176)$ & $(0.386)$ & $-2.629^{* *}$ \\
& $-0.856^{* *}$ & -0.654 & $(1.258)$ \\
Physicians share & $(0.414)$ & $(0.616)$ & -1.416 \\
& -0.480 & -0.288 & $(0.959)$ \\
Nurses share & $(0.306)$ & $(0.467)$ & Yes \\
(omitted base is health care assistants) & & Yes \\
& & No & Yes \\
Hospital fixed effects & No & Yes & Yes \\
Casemix controls (14) & Yes & Yes & 0.000 \\
Year dummies (6) & Yes & No & 0.142 \\
Region dummies (10) & Yes & & 0.923 \\
SC(1) p-value & & & 210 \\
SC(2) p-value & & 133 & 901 \\
Hansen-Sargan p-value & 210 & 345 & \\
No of Hospitals & 901 & & \\
Observations & & & \\
\hline \hline
\end{tabular}

Notes: * significant at $10 \%$; ** significant at $5 \%$; *** significant at $1 \%$

Quality is measured by the within hospital deaths within 30 days of emergency admission for acute myocardial infarction (AMI) for over 55 year olds admitted to the hospital. Casemix controls are the proportion of total emergency admissions for AMI made up by each 5-year age-gender band from age 55 upwards. All regressions control for area mortality rates, (lagged) employment and hospital type (i.e. whether the acute hospital was a specialist hospital, teaching hospital or "normal” hospital). Longdifferences are three- year annual average growth rates. In the System-GMM estimates, one-step robust estimates are presented equations are levels of own values t- 2 through t-5; instruments in the levels equations are once lagged differences. SC(k) is Arellano-Bond (1991) test of serial correlation. Physician share, nurse share and total employment are treated as endogenous (the outside wage is lagged and treated as exogenous). We also use the lagged predicted inside wage as an instrument. In the GMM specification instruments in the differenced of order $k$ of the first differenced residuals. Sargan-Hansen is a test of all the over-identifying restrictions. Time period is 19962001. Standard errors in parentheses under coefficients are robust to arbitrary heteroskedacity and autocorrelation. 
Table 3: Productivity in hospitals and the outside wage

\begin{tabular}{|c|c|c|c|}
\hline $\begin{array}{l}\text { Dependent variable } \\
\text { Estimation technique }\end{array}$ & $\begin{array}{l}\text { Ln(Productivity) } \\
\text { OLS } \\
(1) \\
\end{array}$ & $\begin{array}{l}\text { Ln(Productivity) } \\
3 \text { year annual Long Differences } \\
\text { (2) }\end{array}$ & $\begin{array}{l}\text { Ln(Productivity) } \\
\text { GMM-SYS } \\
\text { (3) }\end{array}$ \\
\hline Ln (Area outside wage) & $\begin{array}{l}-0.658 * * * \\
(0.198)\end{array}$ & $\begin{array}{l}0.252 \\
(0.279)\end{array}$ & $\begin{array}{l}-0.551 * * * \\
(0.181)\end{array}$ \\
\hline Physicians share & $\begin{array}{l}3.837 * * * \\
(0.484)\end{array}$ & $\begin{array}{l}0.248 \\
(0.411)\end{array}$ & $\begin{array}{l}3.909 * * * \\
(0.898)\end{array}$ \\
\hline Nurses share & $\begin{array}{l}0.386 \\
(0.278)\end{array}$ & $\begin{array}{l}0.006 \\
(0.216)\end{array}$ & $\begin{array}{l}1.736 * * * \\
(0.627)\end{array}$ \\
\hline \multicolumn{4}{|c|}{ (omitted base is health care assistants) } \\
\hline Hospital fixed effects & No & No & Yes \\
\hline Casemix controls (39) & Yes & Yes & Yes \\
\hline Year dummies (6) & Yes & Yes & Yes \\
\hline Region dummies (10) & Yes & No & Yes \\
\hline SC(1) p-value & & & 0.004 \\
\hline SC(2) p-value & & & 0.462 \\
\hline Hansen-Sargan p-value & & & 0.042 \\
\hline No of Hospitals & 210 & 133 & 210 \\
\hline Observations & 901 & 345 & 901 \\
\hline
\end{tabular}

Notes: *significant at 10\%; ** significant at 5\%; *** significant at 1\%. Productivity measured as the number of Finished Consultant Episodes (FCEs) per whole-time equivalent (WTE) employee; casemix controls are proportion of admissions in five year age-gender cells and the proportions of admissions that are (a) elective, (b) emergency or (c) transfers. All regressions control for area mortality rates, (lagged) employment size and hospital type (i.e. whether the acute hospital was a specialist hospital, teaching hospital or "normal” acute hospital). Long-differences are three-year annual average growth rates. In the System-GMM estimates, one-step robust estimates are presented. Physician share, nurse share and total employment are treated as endogenous (the outside wage is lagged and treated as exogenous). We also use the lagged predicted inside wage as an instrument. In the GMM specification instruments in the differenced equations are levels of own values t-2 through t-5; instruments in the levels equations are once lagged differences. SC $(k)$ is Arellano-Bond (1991) test of serial correlation of order $k$ of the first differenced residuals. Sargan-Hansen is a test of the over-identifying restrictions. Standard errors in parentheses under coefficients are robust to arbitrary heteroskedacity and autocorrelation. 
Table 4: Controlling for the inside wage

\begin{tabular}{|c|c|c|c|c|c|c|}
\hline $\begin{array}{l}\text { Dependent } \\
\text { variable }\end{array}$ & $\begin{array}{l}\text { Ln(AMI Death } \\
\text { Rate) }\end{array}$ & $\begin{array}{l}\text { Ln(AMI Death } \\
\text { Rate) }\end{array}$ & $\begin{array}{l}\text { Ln(AMI Death } \\
\text { Rate) }\end{array}$ & Ln(Productivity) & L"Ln(Productivity) & Ln(Productivity) \\
\hline \multirow{2}{*}{$\begin{array}{l}\text { Ln (Area outside } \\
\text { wage) }\end{array}$} & $0.406^{* *}$ & $0.765^{* *}$ & $0.431^{* *}$ & $-0.659 * * *$ & 0.244 & $-0.547 * * *$ \\
\hline & $(0.171)$ & $(0.384)$ & $(0.172)$ & $(0.195)$ & $(0.282)$ & $(0.172)$ \\
\hline $\begin{array}{l}\text { Average inside } \\
\text { wage }\end{array}$ & $-0.286 * *$ & -0.126 & $-0.334 * *$ & 0.071 & 0.097 & $0.241 * *$ \\
\hline Physicians share & $(0.443)$ & $(0.641)$ & $(1.236)$ & $(0.533)$ & $(0.394)$ & $(0.930)$ \\
\hline \multirow[t]{2}{*}{ Nurses share } & -0.313 & -0.253 & -0.910 & 0.347 & 0.004 & $1.680 * * *$ \\
\hline & $(0.299)$ & $(0.471)$ & $(0.822)$ & $(0.270)$ & $(0.212)$ & $(0.607)$ \\
\hline SC(1) p-value & & & 0.000 & & & 0.002 \\
\hline SC(2) p-value & & & 0.162 & & & 0.436 \\
\hline Hansen- p-value & & & 0.795 & & & 0.081 \\
\hline Hospitals & 211 & 211 & 211 & 211 & 211 & 211 \\
\hline Obs & 901 & 901 & 901 & 901 & 901 & 901 \\
\hline
\end{tabular}


Table 5: The role of agency staff in accounting for the impact of the labor market on hospital quality and productivity

\begin{tabular}{|c|c|c|c|c|c|c|c|}
\hline $\begin{array}{l}\text { Dependent } \\
\text { variable }\end{array}$ & Ln(Agency) & $\operatorname{Ln}(\mathrm{AMI})$ & Ln(AMI) & $\operatorname{Ln}(\mathrm{AMI})$ & $\begin{array}{l}\mathrm{Ln} \\
\text { (productivity) }\end{array}$ & $\begin{array}{l}\text { Ln } \\
\text { (productivity) }\end{array}$ & $\begin{array}{c}\text { Ln } \\
\text { (productivity) }\end{array}$ \\
\hline & $(1)$ & $(2)$ & (3) & $(4)$ & (5) & (6) & (7) \\
\hline Ln (Area & $2.851 * *$ & & $0.314^{*}$ & 0.175 & & $-0.805 * * *$ & $-0.729 * * *$ \\
\hline outside wage) & (1.138) & & $(0.170)$ & $(0.202)$ & & $(0.182)$ & $(0.194)$ \\
\hline Ln(Inside & 0.077 & & $-0.494 * * *$ & $-0.477^{* * *}$ & & 0.219 & $0.296 * *$ \\
\hline wage) & (1.045) & & $(0.153)$ & $(0.161)$ & & $(0.134)$ & $(0.141)$ \\
\hline Ln(Agency) & & $0.057 * *$ & & $0.046 *$ & $-0.106 * * *$ & & $-0.057 * * *$ \\
\hline & & $(0.026)$ & & $(0.024)$ & $(0.027)$ & & $(0.018)$ \\
\hline SC(1) p-value & 0.799 & 0.006 & 0.002 & 0.006 & 0.006 & 0.011 & 0.043 \\
\hline SC(2) p-value & 0.130 & 0.983 & 0.485 & 0.921 & 0.355 & 0.488 & 0.944 \\
\hline $\begin{array}{l}\text { Hospital fixed } \\
\text { effects }\end{array}$ & Yes & Yes & Yes & Yes & Yes & Yes & Yes \\
\hline $\begin{array}{l}\text { Year dummies } \\
\text { (6) }\end{array}$ & Yes & Yes & Yes & Yes & Yes & Yes & Yes \\
\hline $\begin{array}{l}\text { Region } \\
\text { dummies (10) }\end{array}$ & Yes & Yes & Yes & Yes & Yes & Yes & Yes \\
\hline Hansen p-value & 0.377 & 0.178 & 0.651 & 0.314 & 0.379 & 0.351 & 0.471 \\
\hline No. of hospitals & 176 & 176 & 176 & 176 & 176 & 176 & 176 \\
\hline Observations & 523 & 520 & 520 & 520 & 520 & 520 & 520 \\
\hline
\end{tabular}

Notes: *significant at 10\%; ** significant at 5\%; *** significant at 1\%. "Agency” Expenditure is the share of total staff expenditure that is accounted for by expenditure on non-NHS nursing staff. Productivity measured as the number of Finished Consultant Episodes (FCEs) per whole-time equivalent (WTE) employee. Quality is measured by the within hospital deaths within 30 days of emergency admission for acute myocardial infarction (AMI) for over 55 year olds admitted with AMI to the hospital. Physician share, nurse share, employment size, agency (except in columns (3) and (5) where agency is excluded) and inside wage (except in columns (2) and (5) where we exclude inside wages) are treated as endogenous. All columns are estimated by System GMM (instruments in the differenced equations are levels of own values t-2 through t-5; instruments in the levels equations are once lagged differences). Column (3) is an identical specification to column (3) of Table 4 and column (6) is an identical specification to column (6) of Table 5 except we estimate on the sub-sample where we observe agency staff expenditure. All standard errors are robust to arbitrary heteroskedacity and autocorrelation; in the System-GMM estimates one step robust estimates are presented and all staff variables are treated as endogenous (outside wage is lagged and treated as exogenous). SC $(k)$ is Arellano-Bond (1991) test of serial correlation of order $k$ of the first differenced residuals. Sample size is larger in column (1) because we do not condition on lagged agency as we do in other columns. 
Table 6: A Placebo experiment - productivity and outside wages in nursing homes for senior citizens

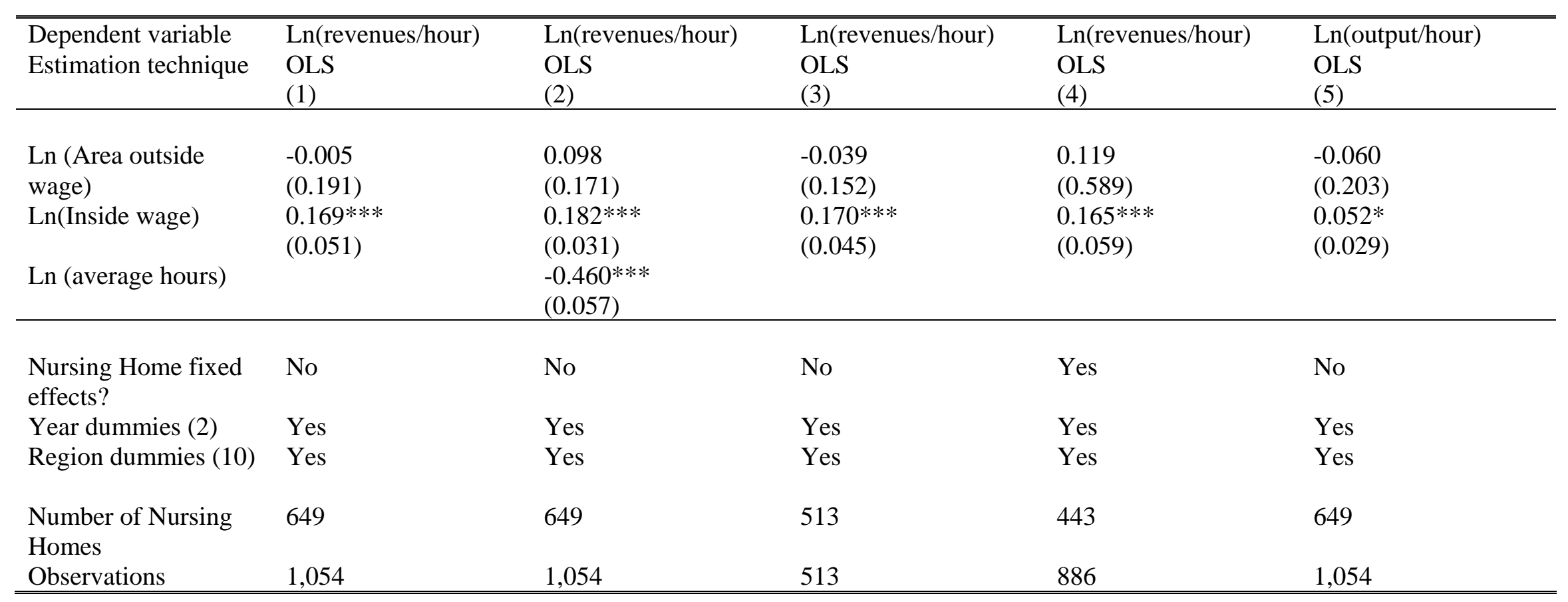

Notes: *significant at 10\%; ** significant at 5\%; *** significant at $1 \%$. Productivity measured in columns (1) through (4) by revenues divided by hours. Revenues measured by the number of occupied beds multiplied by average price per bed. Output is simply the number of occupied beds. Hours are total hours worked. All regressions control for proportion of qualified nurses, proportion of female, average age of worker, a quintic in size of the nursing home (measured by employees), the proportion of residents who are paid for by the government, regional dummies and year dummies. Standard errors are clustered by nursing home. Data is from UK nursing homes in 1998 and 1999 (see Machin and Wilson, 2004), except for column (3) which is on 1998 only. 
Table 7: Robustness tests - coefficient (standard error) on outside wage

\begin{tabular}{|c|c|c|c|c|}
\hline \multirow{2}{*}{\multicolumn{2}{|c|}{ "Dependent variable }} & $\operatorname{Ln}(\mathrm{AMI})$ & Ln(Productivity) & Observations \\
\hline & & $(1)$ & $(2)$ & $(3)$ \\
\hline 1 & Baseline & $\begin{array}{l}0.460 * * \\
(0.175) \\
\end{array}$ & $\begin{array}{l}-0.547 * * * \\
(0.172)\end{array}$ & 901 \\
\hline 2 & Additional casemix controls & $\begin{array}{l}0.427 * * * \\
(0.170)\end{array}$ & $\begin{array}{l}-0.556 * * * \\
(0.153)\end{array}$ & $\begin{array}{l}900 \text { (for AMI) } \\
892 \text { (for productivity) }\end{array}$ \\
\hline 3 & Include hospital financial surplus & $\begin{array}{l}0.399 * * \\
(0.182)\end{array}$ & $\begin{array}{l}-0.516 * * * \\
(0.184)\end{array}$ & 745 \\
\hline 4 & $\begin{array}{l}\text { Include lagged dependent variable: long-run } \\
\text { [p-value] }\end{array}$ & $\begin{array}{l}0.508 * * * \\
{[0.008]}\end{array}$ & $\begin{array}{l}-0.572 * * * \\
{[0.020]}\end{array}$ & 901 \\
\hline 5 & Drop Inner and Outer London & $\begin{array}{l}0.304^{* *} \\
(0.156)\end{array}$ & $\begin{array}{l}-0.383^{* *} \\
(0.173)\end{array}$ & 776 \\
\hline 6 & Drop big jumps in outside wage & $\begin{array}{l}0.530 * * \\
(0.197)\end{array}$ & $\begin{array}{l}-0.622 * * * \\
(0.167)\end{array}$ & 885 \\
\hline 7 & Balanced Panel & $\begin{array}{l}0.600 * * * \\
(0.207)\end{array}$ & $\begin{array}{l}-0.612 * * * \\
(0.163)\end{array}$ & 582 \\
\hline 8 & Regional outside wage & $\begin{array}{l}0.609 \\
(1.022) \\
\end{array}$ & $\begin{array}{l}-0.445 \\
(0.587)\end{array}$ & 901 \\
\hline 9 & $\begin{array}{l}\text { Regional outside wage (drop regional } \\
\text { dummies) }\end{array}$ & $\begin{array}{l}0.520 * * * \\
(0.172)\end{array}$ & $\begin{array}{l}-0.493^{* *} \\
(0.169)\end{array}$ & 901 \\
\hline 10 & $\begin{array}{l}\text { Include alternative total hospital employment } \\
\text { measure }\end{array}$ & $\begin{array}{l}0.404^{* *} \\
(0.160)\end{array}$ & $\begin{array}{l}-0.540 * * \\
(0.170)\end{array}$ & 901 \\
\hline 11 & $\begin{array}{l}\text { Include higher order and cross product terms } \\
\text { in skill shares }\end{array}$ & $\begin{array}{l}0.541^{* * *} \\
(0.200)\end{array}$ & $\begin{array}{l}-0.637 * * * \\
(0.181) \\
\end{array}$ & 901 \\
\hline
\end{tabular}

Notes: *significant at $10 \%$; ** significant at $5 \%$; *** significant at $1 \%$. Each cell reports the coefficient and robust standard error from a separate system GMM regression. Productivity measured as the number of Finished Consultant Episodes (FCEs) per whole-time equivalent (WTE) employee; Quality is measured by the within hospital deaths within 30 days of emergency admission for acute myocardial infarction (AMI) for over 55 year olds admitted with AMI to the hospital. All regressions have the same System GMM estimation and specifications as follows: column (1) equivalent to Table 2 column (3); column (2) is equivalent to column (3) of Table 3. Outside wage is (lagged) area wage unless elsewhere specified. See text for exact experiments. 


\section{Figure 1: Hypothetical impact of regulated wage on the labor market}

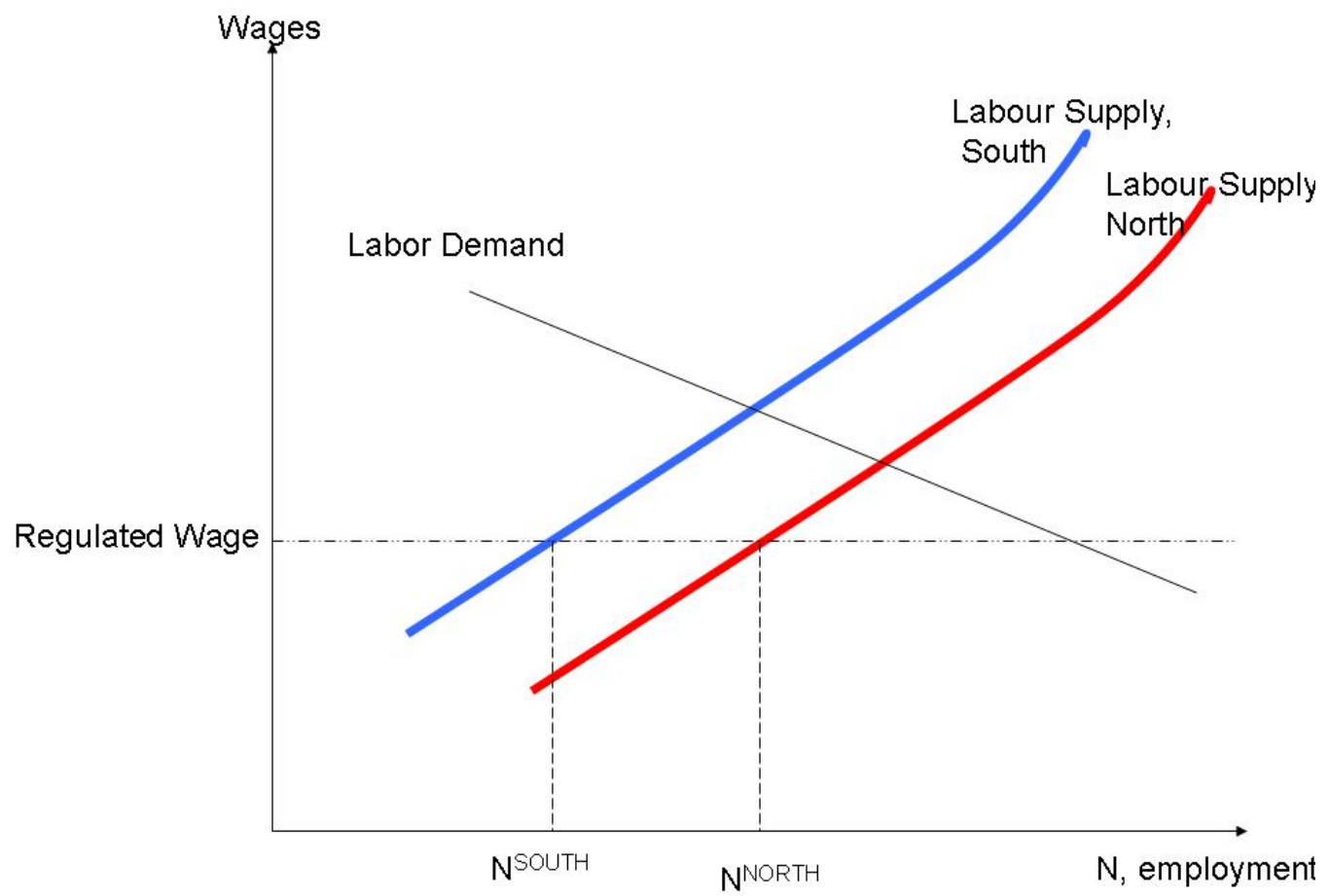

Notes: The theoretical impact of a nationally regulated wage on NHS labor supply in two areas with different outside labor markets. South (e.g. London area) has a stronger outside labor market with higher alternative wages than North, so the supply curve lies to the left. A single nationally fixed wage (so long as it is below the competitive level) will result in a lower number of employees in the South than in the North. 
Figure 2: The role of private sector temporary agency nurses

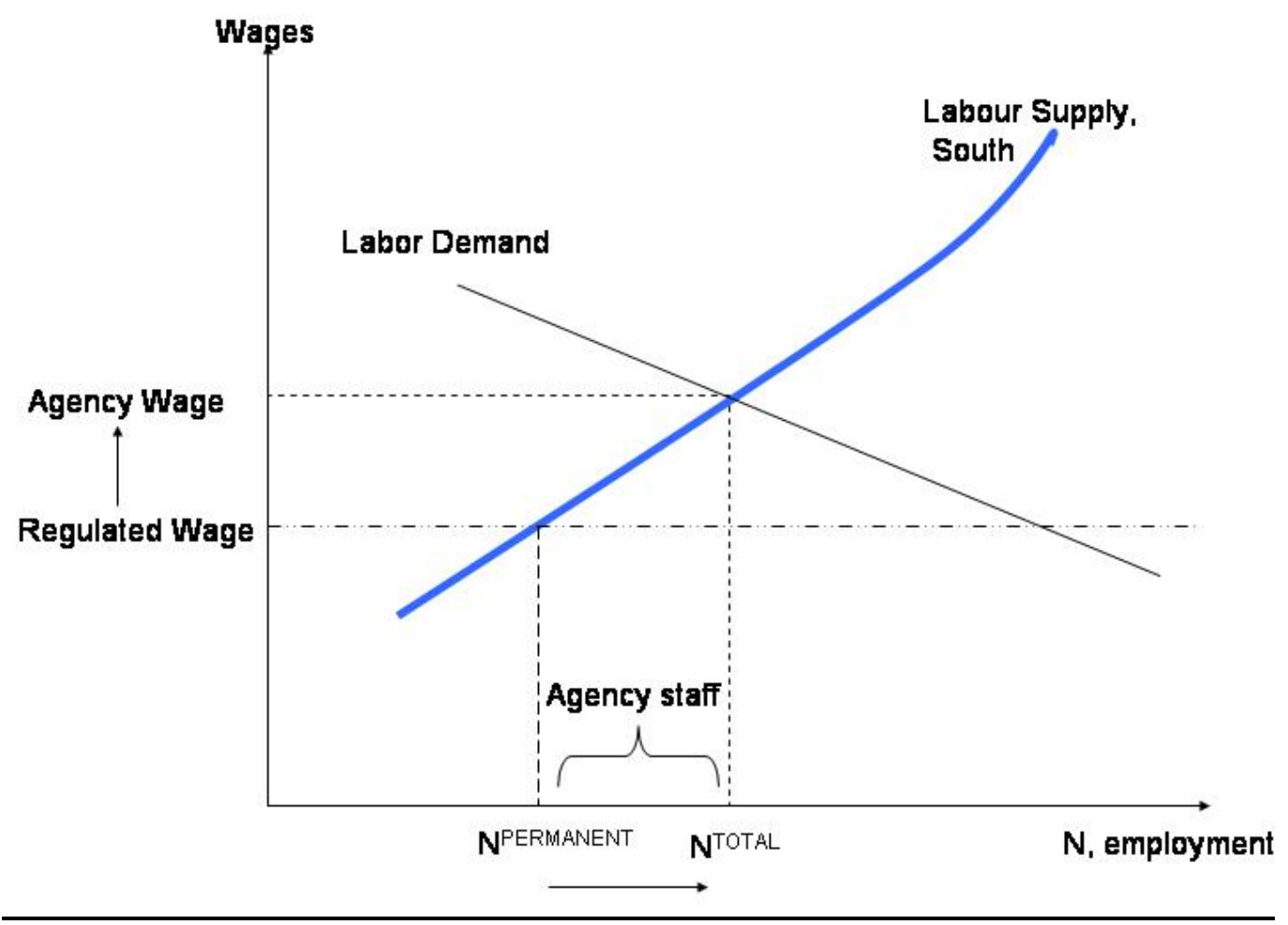

Notes: This describes the possible reaction of hospitals to a mandated wage when there is also the possibility of hiring temporary agency staff whose wages are not restricted by the regulation mandated to permanent staff. In the face of a regulated wage and a competitive market for agency nurses, the agency wage will rise and employment will from $\mathbf{N}^{\text {PERMANENT }}$ to $\mathbf{N}^{\text {TOTAL }}$ 
Figure 3: The distribution of death rates from AMI across hospitals, 1995-2002

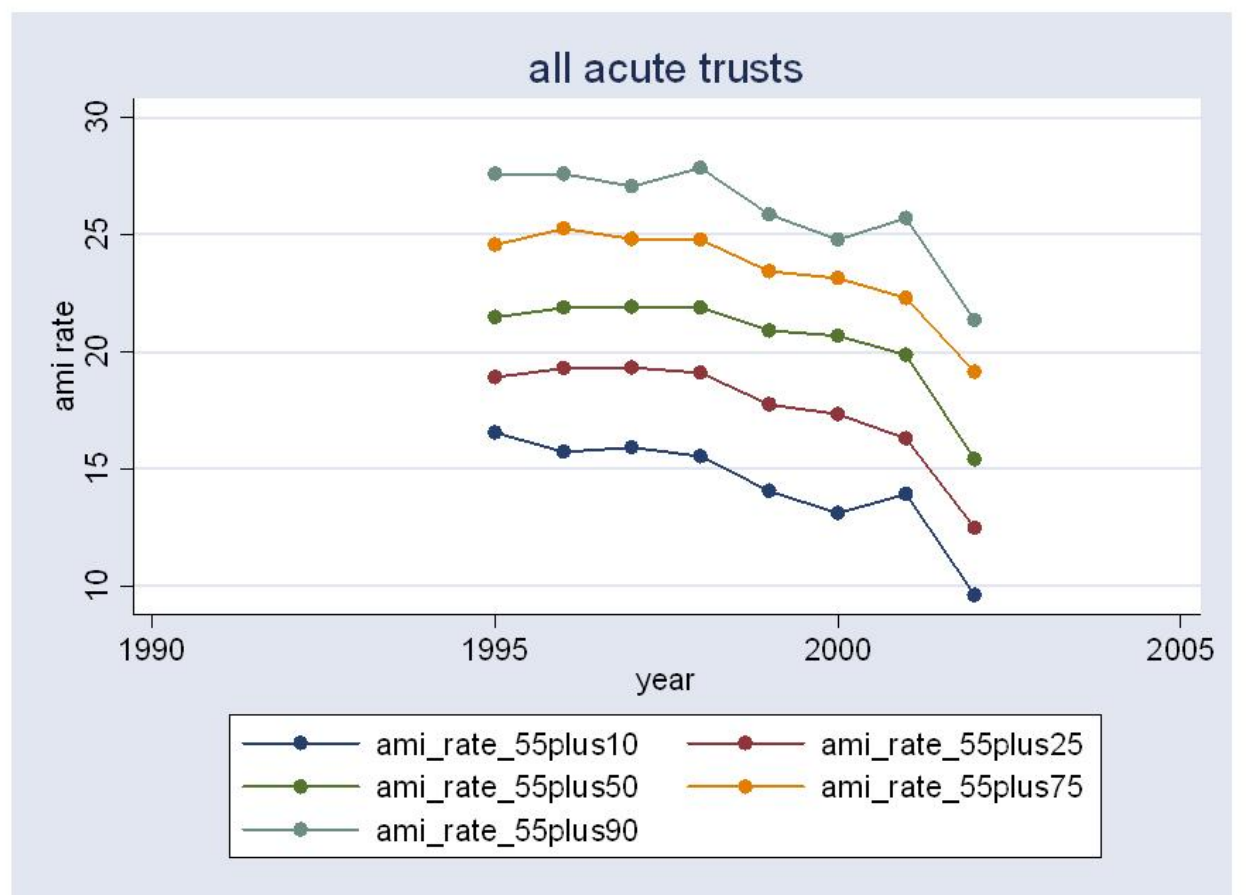

Notes: Data for full panel of acute hospital trusts. The top line shows the evolution of AMI death rates at the $10^{\text {th }}$ percentile (highest death rates) and the bottom line the evolution of death rates at the $90^{\text {th }}$ percentile (lowest death rates). 
Figure 4: The distribution of productivity (Finished Consultant Episodes per clinical staff member) across hospitals, 1995-2002

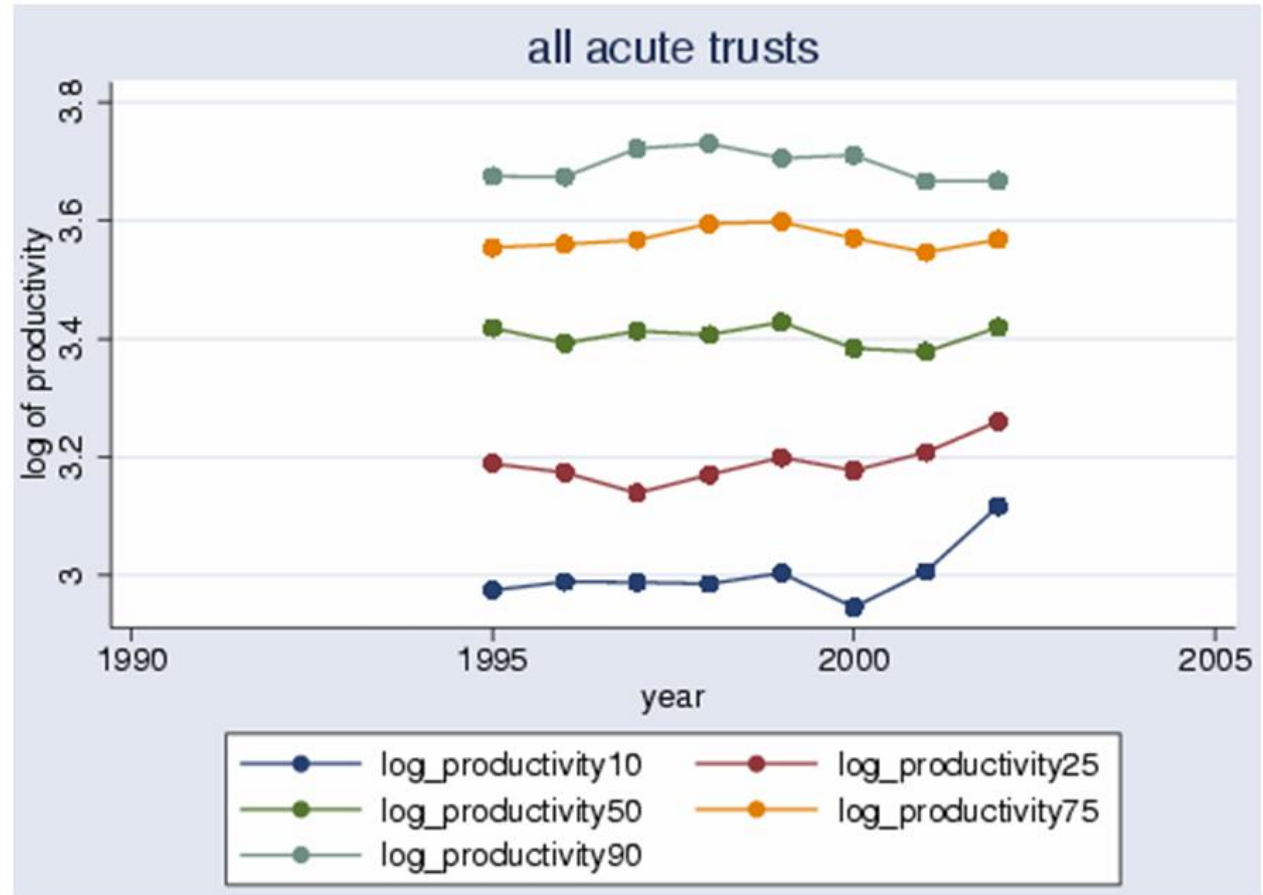

Notes: Data for the full sample of acute hospital trusts. The top line shows the evolution of $\ln$ (productivity) at the $90^{\text {th }}$ percentile (highest productivity) and the bottom line the evolution of $\ln$ (productivity) at the $10^{\text {th }}$ percentile (lowest productivity). 
Figure 5: Distribution of outside wages, intensity of use of agency nurses and AMI death rates in England
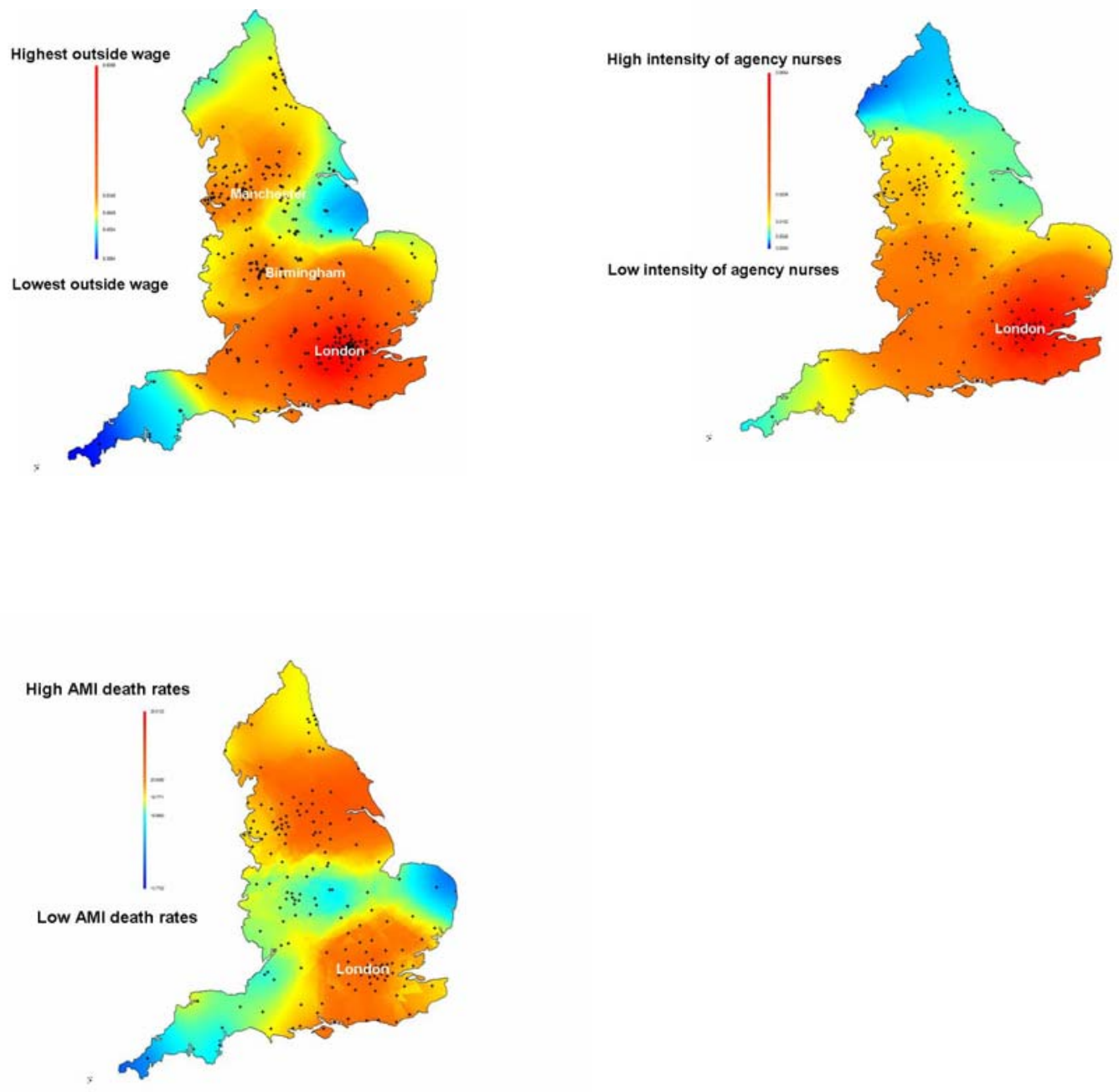

Notes: Data are 1996-2001 averages. Outside pay is the average ln wages of all female non-manual workers (from New Earnings Survey). Intensity of use of agency nurses is the proportion of employees who are agency staff. AMI rates are within hospital deaths within 30 days of emergency admission for acute myocardial infarction for over 55 year olds admitted with AMI to the hospital. 
Figure 6: Nurse vacancy rates and outside wages

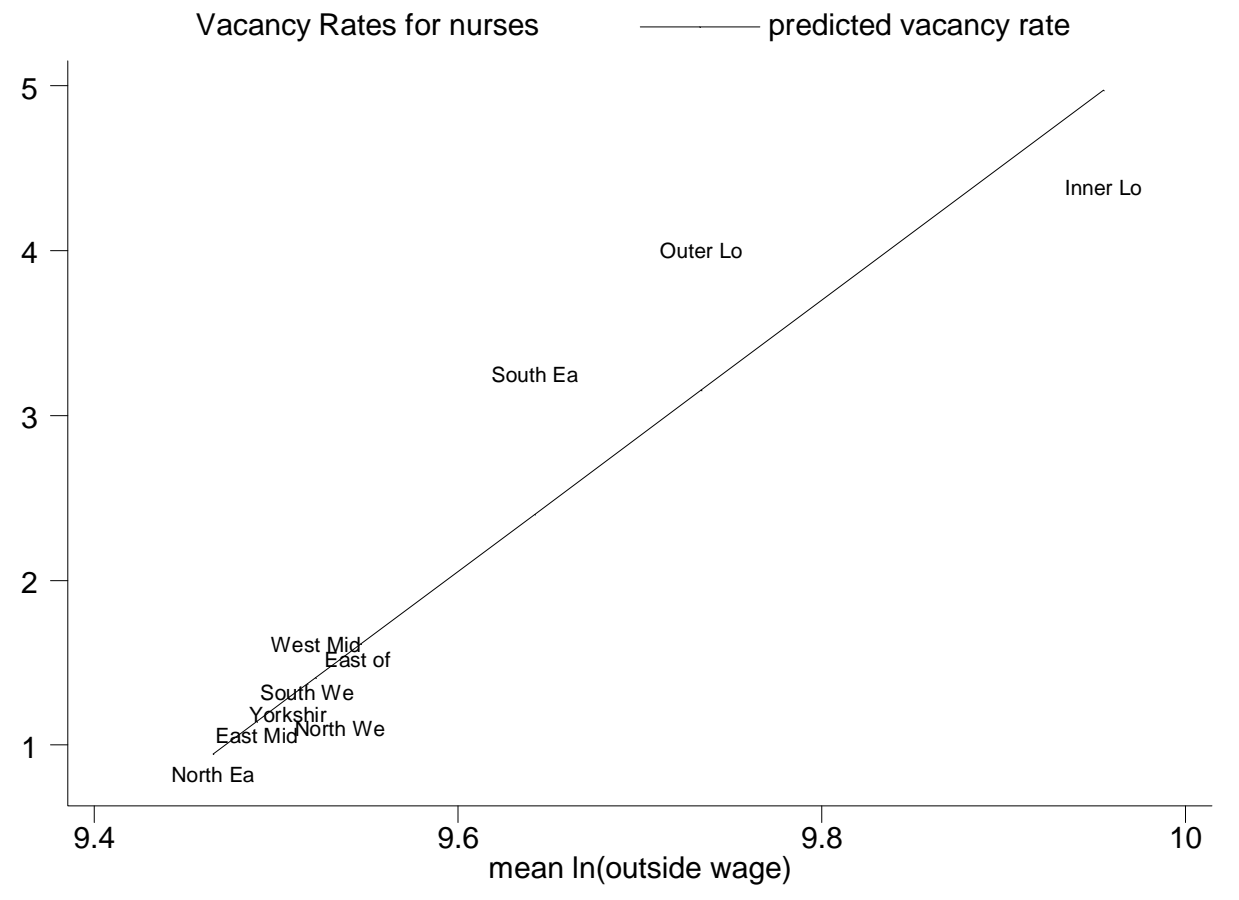

Notes: Each observation is one of the ten regions in England (the average region has $4.9 \mathrm{~m}$ people and we have a $1 \%$ example of workers from the New Earnings Survey). Outside pay is the average $\ln$ wages of all female non-manual workers (from New Earnings survey). Vacancy rates are the proportion of nurse posts that have been vacant for three months or more (Office of Manpower Economics, 2003). 1996-2001 averages. The straight line is the prediction from a linear regression. 
Figure 7: Intensity of use of agency nurses and outside wages

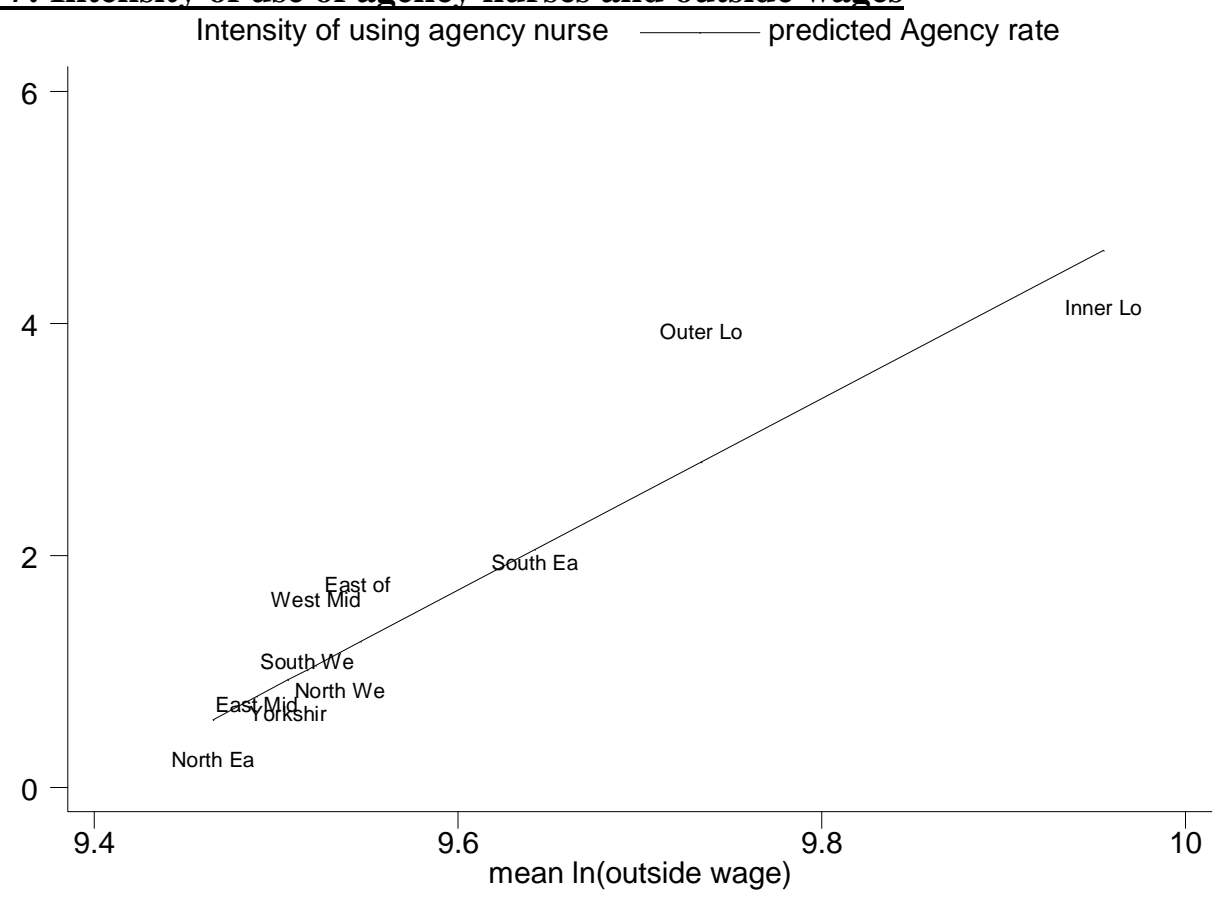

Notes: Each observation is one of the ten regions in England. Outside pay is the average ln wage of all female non-manual workers. Intensity of use of agency nurses is the proportion of employees who are agency staff. 1996-2001 averages. The straight line is the prediction from a linear regression. 
Figure 8: AMI death rates and outside wages

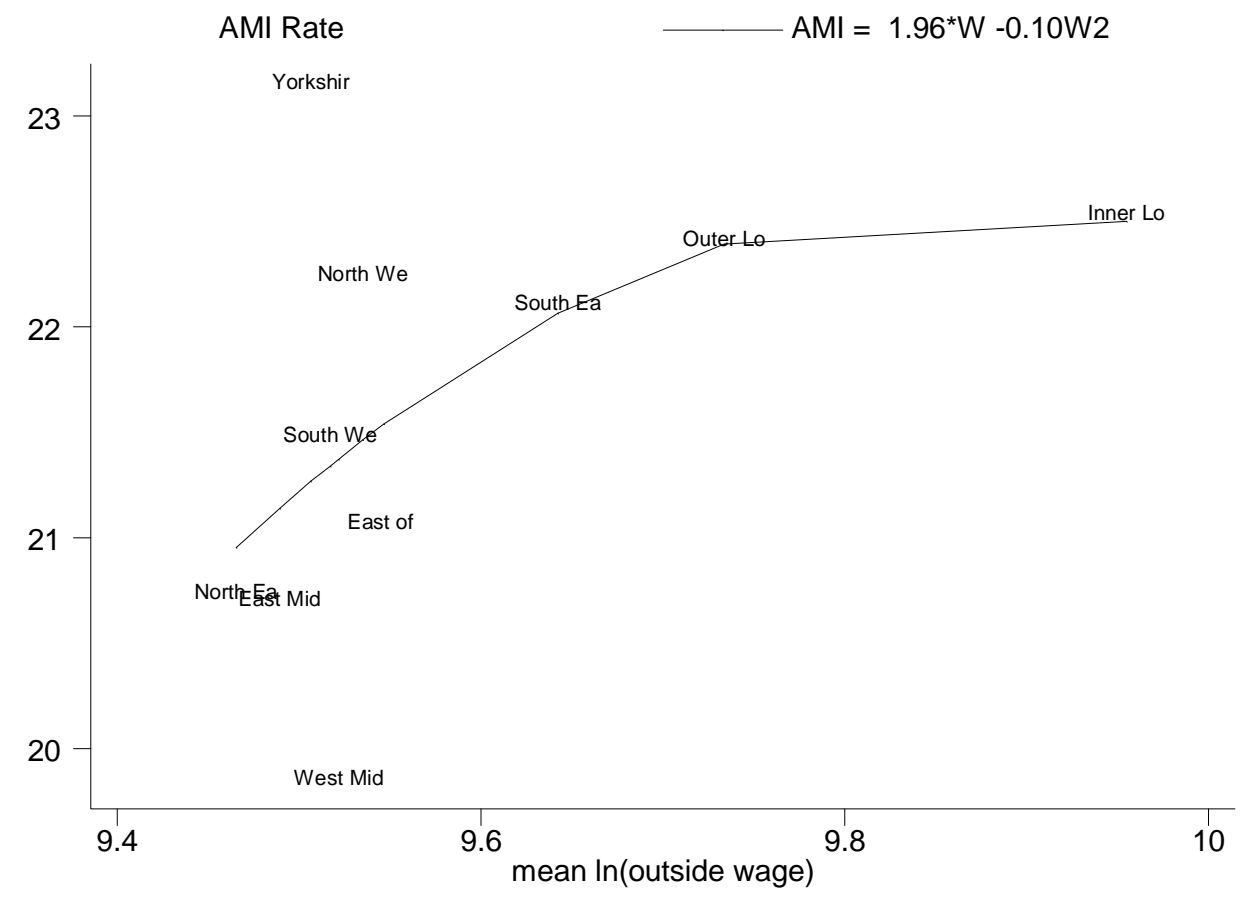

Notes: Each observation is one of the ten regions in England. Outside pay is the average ln wage of all female non-manual workers. AMI rates are within hospital deaths within 30 days of emergency admission for acute myocardial infarction for over 55 year olds admitted with AMI to the hospital. 1996-2001 averages. The curved line is the predictions from a regression of AMI death rates on the level and square of the $\ln$ (outside wage). 
Figure 9: Changes in AMI death rates and changes in outside wages

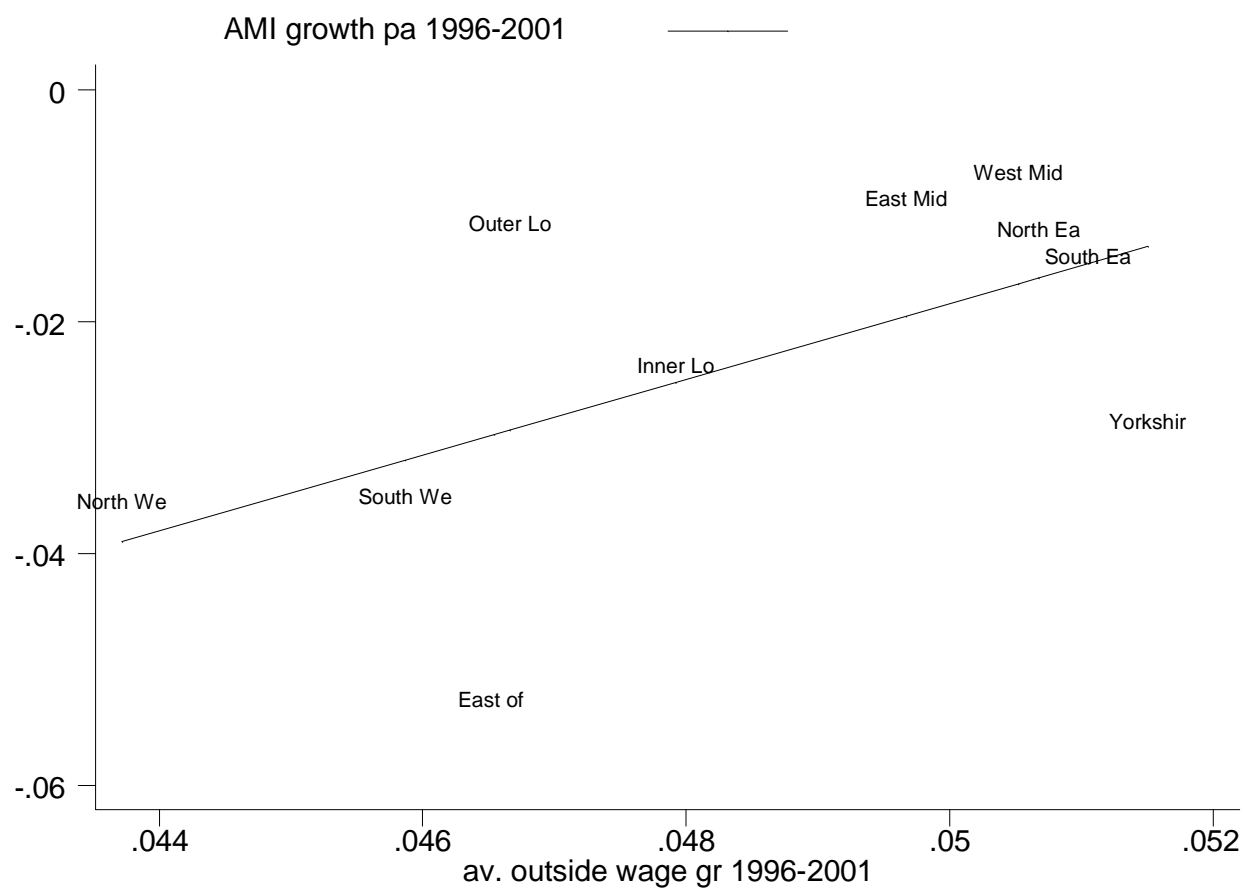

Notes: Each observation is one of the ten regions in England. Outside pay is the average ln wage of all female non-manual workers. AMI rates are within hospital deaths within 30 days of emergency admission for acute myocardial infarction for over 55 year olds admitted with AMI to the hospital. The variables are the growth rates between 1996 and 2001. The straight line is the prediction from a linear regression. 
Appendix A: Brief review of literature on the impact of skills in hospital production and the responsiveness of medical labor supply to wages

\section{A1. The impact of medical staff on hospital output}

There is a growing literature on the importance of nurses in hospital production, although less focus on the impact of physicians. Jensen and Morrissey (1986) is one of the few papers that focus directly on the impact of physicians on hospital productivity. They find that increases in physicians increased hospital output, but by less than increases in nurses (although by more than medical residents). This is surprising as physicians have longer in training and therefore are likely to have higher human capital. However, since the period covered by the data in this study, the amount of training received by nurses has risen and there has been considerable technological change in hospital production.

Most of the literature on the impact of nurses on patient outcomes is from the US (see Curtin, 2003, for a recent review). Cross sectional studies dominate the literature and tend to find a significant effect of nurse labor on outcomes. Aiken et al. (2002) using a large cross section of acute care Pennsylvanian hospitals, examine the relationship between two measures of patient care (deaths within 30 days of admission and 'failure to rescue') and nurse staffing ratios (the average number of patients in a nurse's workload). They find an effect of nurse staffing on both outcomes: the odds of patient mortality increased by $7 \%$ for every additional patient in the average nurse's workload in the hospital. Aiken et al. (2003) finds a positive relationship between education level and patient mortality Needleman et al. (2002) study over 5 million patient discharges from 799 hospitals in 11 states and use several measures of patient outcomes and hours of nursing care per day (adjusted for the severity of the casemix). They found a strong and consistent relationship between hours of nurse staffing and five outcomes for medical patients. These - and most - studies on the impact of nurses on quality of care use cross sectional data, so are unable to control for unobserved heterogeneity between hospitals. It is not clear a priori how this may bias the results: hospitals with high levels of staffing may be better hospitals, so generating an upward bias. Alternatively, they may attract sicker patients, so generating a downward bias. Bartel et al (2007) do use panel data and examine the relationship between job specific capital of nursing staff and patient outcomes, arguing that job specific capital is likely to impact upon the quality of the care provided in hospital settings. Their analysis focuses on registered nurses (RNs) in intensive care units in 70 Veteran Association hospitals between 2003 and 2006. They examine two measures of patient outcomes and define three measures of job specific capital. They find one of these - tenure of the RN in the hospital - is correlated with one measure of patient outcomes (infection rates) allowing for unobserved features of the Intensive Care Unit. However, they are unable to control for experience as well as tenure; thus tenure may be a marker for general nurse experience rather than unit specific capital. Mark et al (2004) also uses panel data and finds little evidence of a causal relationship between nurse staffing and hospital mortality.

\section{A2. Is the labor supply of nurses responsive to labor market conditions?}

Antonazzo et al (2003) review empirical evidence of nursing labor supply. The estimates (mainly from North American studies) display a large degree of variation. Most of the studies are of hours, rather than participation per se. Most studies point to a shortage of nurses; a recent summary of trends in the US market is provided by Buerhaus et al (2004). In the UK, the hours margin is relatively inflexible as there is little choice in the number of hours worked per week in the NHS. Skatun et al (2005) and Frijters et al (2003) both use longitudinal data from the Quarterly Labor Force Survey (QLFS). Frijters et al (2003) look at quitting decision and conclude that wages have a small effect relative to non-wage factors. Skatun et al (2005) look at labor market participation (but not at occupational choice between nursing and other in work options). Both these papers find that the wage elasticity of participation is below unity; the estimates in Frijters et al are less than under 0.1.

On the other hand, Gosling and Van Reenen (2005) use the structure of pay determination for public sector nurses to identify the impact of wages on participation in nursing. This approach deals with the endogeneity of wages by using regulatory decisions as an instrumental variable for the observed wage in a (selection adjusted) participation equation. They also allow for the participation choice to include working in another profession, rather than simply to be not-working. They find estimates of the elasticity of wage on employment elasticities are biased downwards in OLS and reasonably large in their IV results, typically around unity. And research in another setting in which wages for nurses are 
set centrally - Norway - which uses panel data also finds nurses' labor supply responds to wages (and other factors): see Askildsen et al (2002) and Holmas (2002).

Finally, Elliot et al (2007) uses a sample of English hospitals for the years 1999-2002 and examines the association between the average (over the four years) wage gap between nurses pay and that of comparable women at regional level and the nursing vacancy rate at hospital level. They find that higher levels of the wage gap are positively associated with higher vacancy rates. They do not exploit the panel nature of their data, so do not to control for heterogeneity across hospitals.

\section{Appendix B: Data Description}

Data sources for all variables are contained in Table A1.

\section{B1. Sample of hospitals}

We use data from financial year 1995/6 onwards referring to “1995”, etc. as indicating the 1995/6 financial year. Trust data pre-1995/6 is only for those hospitals that had been given freestanding financial status within the NHS prior to that date. By 1995/6 almost all hospitals had freestanding status; before that date the finances (and so expenditure data) for some were still recorded at District Health Authority level. AMI episodes (from HES) were subject to recoding (a change in ICD codes) in 1994/5. We use only acute trusts for the analysis as there are very few non-acute trusts with over 150 AMI admissions in a year. The results are robust to inclusion of these non-acute trusts. Consequently we do not have specialist or mental health trusts in the data. We include dummy variables in all the regressions to control for teaching hospitals.

Use of AMI death rates as a measure of low hospital quality

We use the "30-day" death rate for acute myocardial infarction (AMI). This measures in-hospital deaths within 30 days of emergency admission with a myocardial infarction for patients aged 55 and over. There are several issues in using this measure. The first is the variability in rates: death rates may be quite variable over time hospital-by-hospital, reflecting, in part, small denominators (hospitals may treat relatively few patients in any one year). This noise in the measures of death rates can lead to misclassification of the quality of hospitals (McClellan and Staiger, 1999). Propper et al (2007) conclude that raw UK hospital level rates exhibit considerably less variability than the raw US data, but not than the US rates which have been 'filtered' to reduce noise. To reduce misclassification based on small sample sizes, we omit all hospitals with less than 150 emergency AMI admissions in any one year

The second issue is that we use the thirty-day rate itself. The seven day rate was not available until 1999, but it is highly correlated with the thirty-day rate and results using this as the dependent variable show similar patterns. We were also concerned that some patients may die after thirty days and we are missing these deaths. Examination of the distribution of AMI deaths in hospitals from other sources, however, shows that about half of deaths from AMI occur within the first day of admission (see Table A2 below). 98\% of the deaths occur within the first thirty days. Consequently the thirty-day window is more than adequate.

The third issue arises because our measure is the death rates within a hospital. Deaths occurring after transfer to another provider are credited to the provider where the patient was first admitted, whilst deaths following discharge are omitted. This may bias the results if hospitals have a motive to discharge early. Such incentives would have been small as these death rates were not published until 1999 and hospitals not ranked by the Department of Health in terms of outcomes until 2001, when they were ranked on a composite bundle of over twenty indicators. Finally, in richer areas hospitals it may be possible that there are earlier discharges because patients have more care available. This would bias our results against finding an effect of the outside wage on AMI in hospital deaths.

We lose 1995 because of the need to use lagged values in some regressions. Starting with 1,000 acute hospital-year observations after cleaning, we lose 83 observations because of the condition to have 150 AMI admissions. We lose 10 observations because of the need for continuous series. 


\section{B2. Wages}

(a) Inside Wage

Out main measure of the inside wage is the average hourly clinical wage. This is constructed by dividing the clinical wage bill by whole time equivalent hours. We also considered the wages of individual groups of workers separately, but found these variables insignificant once we controlled for overall clinical wage.

\section{(b) Regulation}

To get an idea of the regulated pay structure consider nurse pay scales at $1^{\text {st }}$ April 1999. Clinical grades range from A to I and correspond to spinal points 3 to 37 (see Table A3). For example, Clinical Grade G, a "district nurse" corresponds to a grade between spinal points 12 (£20,145 per annum) to spinal point 9 (£23,300 per annum). There are allowances (or “weightings”) for being in high cost areas. For Inner London this was $£ 2,205$ plus $5 \%$ of salary up to a maximum of $£ 750$, for Outer London this was 1570 plus $5 \%$ of salary up to a maximum of $£ 750$ and for the "fringe" (various areas in the South East) this was $£ 285$ plus $2.5 \%$ of salary up to a maximum of $£ 375$. For a senior nurse on $£ 23,300$ a year working in the most expensive area of the UK, Inner London, and the extra regional allowance would be worth only $11 \%$ more salary $(£ 2,205+£ 750 /(£ 2,205+£ 750+£ 23,300))$. Since this is capped, for a more senior nurse on a higher salary the proportional value is lower. By contrast, in 1999 in the NES the annual non-manual wage in Inner London is about 65\% higher than that of the North East, the lowest wage region.

In calculating the instrumental variable for inside pay measure we take into account the NHS grade structure in a region in a year (using wage data from the NES). We then use the decisions of the NPRB over the changes in the wage structure taking into account all the London weightings, etc (which may differ by grade) to form the predicted wage in the next period (specific to each region).

\section{(c) Outside Wage}

We use several measures of outside wages. Our main measure is the average wages of non-manual female workers since the overwhelming bulk of nurses are women. Our main measure is derived from the New Earnings Survey (NES) that is a one per cent sample of all employees in Great Britain covering about 300,000 individuals a year. The NES is mandatory administrative panel data provided by firms to the Department of Work and Pensions and contains information on earnings and hours. Our main measure is average annual earnings, but we also consider hourly wages. We use the area code in the NES to construct seventy-eight distinct county-based travel to work areas (or boroughs in London). Using the postcodes of the headquarters of county (and borough) councils, we matched each NHS hospital to all county (borough) councils that fell within a twenty-kilometer radius from the hospital. The local area wage is constructed as the average of the county wages of all the councils that fell into this radius. Where no councils fell within the twenty kilometer radius the wage applicable to the nearest council was used.

As an alternative to the NES we also considered the Labor Force Survey (LFS). The LFS is a selfreported household survey containing about 320,000 individuals per year (with 80,000 observations on wages). From the LFS we can extract spatial wage differentials conditioning on more characteristics to build up the outside wage offered to a "typical" nurse. We experimented with such measures that successfully predict labor supply problems in the cross section (e.g. Elliot et al, 2007). The smaller sample size and sampling variation, however, means that such constructed variables are less useful in a panel data analysis. So for the most part, we rely on the larger sample sizes of the NES that has less measurement error as it is taken directly from employer records. We also experimented with using measures of unemployment rates and employment rates as alternative indicators of labor market "tightness". We did not find that these added explanatory power over and above the information in the wage, which in principle should fully reflect labor market conditions.

\section{B3. Health Episode Statistics (HES) Data}

HES data are used for the AMI, productivity and case mix variables. HES are discharged based records of all inpatient activity delivered in NHS hospitals. The main unit of recording is the Finished Consultant Episode (a period of admitted patient care under a consultant or allied healthcare professional within an NHS trust). This is not always the same as a single stay (spell) in hospital, because a patient may be transferred from one consultant to another during their stay. In these cases, there will be two or more episode records for the spell of treatment. Diagnoses are currently coded 
according to the International Classification of Diseases, 10th Revision (ICD-10) and surgical procedures (operations) according to the Office of Population, Censuses and Surveys: Classification of Surgical Operations and Procedures, fourth Revision (OPCS-4.2). HES records includes further codes - for example, age of the patient ${ }^{55}$.

\section{B4. Case-mix adjustment of FCEs}

For the robustness tests in Table 7 we calculated extra casemix controls. To estimate the casemix adjustment for a hospital, all inpatient spells are allocated to a Healthcare Resource Group (HRG) category. An HRG is a code for a group of clinically similar treatments and care that require similar levels of healthcare resources. They are similar to Diagnostic Related Groups or DRGs in the US. An example of an HRG is renal dialysis, separated into haemodialysis and peritoneal dialysis. HRG codes are derived from ICD-10 and the OPCS 4.2 codes on HES records.

For additional AMI casemix we constructed "AMI with complications" from the proportion of emergency patients 55 years or older admitted with HRG codes E11 (AMI with complications) and E12 (AMI without complications).

For the productivity casemix we begin with a weight representing the expected cost (the reference cost) is attached to each HRG to derive the scalar case mix index for all spells treated over a year for each hospital. The national average case weight is set to equal 100: case mix indices above 100 represent hospitals that have treated a more complex than average mix of cases. The index used here based on reference costs from 1998/99 onwards (when reference costs were first available). Prior to that, the cost weights prior are based on expected costs. Because we are concerned about the precise consistency of this variable before and after 1998, we use it only as a robustness check rather than include it in our main specifications.

\section{B5. Nursing Homes Data}

The nursing (or "care") homes data is discussed in the text and in more detail in Machin and Wilson (2004). Homes were surveyed in 1997 and 1998 (there is also data in 1992 and 1993, but this does not contain the information needed to construct revenue). We observe individual worker data so we can construct various measures of the internal wage structure of the firm. Information was also collected on average price (a quality measure), the proportion of residents who are government subsidised and various demographic characteristics of workers (their qualifications, age, gender, etc.).

Total revenue and profits are not reported directly in the care homes data. We calculated them from the underlying home-specific components. Sales (S) is calculated as Occupancy Proportion* Number of Beds * Average Price (all reported in the survey). Average weekly hours are reported in the survey and our key measure is therefore revenues per hour. We also consider the physical measure of productivity as output per hour ((Occupancy Proportion* Number of Beds)/(hours*workers)). We matched in outside wages using zip codes using exactly the same data and methods as for hospitals.

\section{B6. UK Firm-level panel data}

All incorporated UK firms, both private and public, are obliged to lodge accounts at Companies' House. Bureau Van Dijk (BVD), a private company, supplies this accounting data through its AMADEUS database. We appended the Amadeus DVDs from 1996 to 2006 to generate longitudinal data on living and dead firms from 1988 onwards. From this we selected all firms in two digit industries 53 through 60, 71 through 79 and 81. We ran regressions at the three digit industry level. We chose these because (a) they were service sectors so more comparable with the health sector and (b) they are mainly sectors where there are a relatively large proportion of women workers (like hospitals).

We selected firms who were alive at some point between 1996 and 2001, who had non-missing information for at least one year on employment, wages, sales and capital. We also insisted in having at least 100 observations in each three digit industry. We matched in outside wages using zip codes using exactly the same data and methods as for hospitals. We are left with 63,052 firm-year observations in the overall dataset that we run regressions on.

The full set of results from the industry-specific regressions is contained in Table A4.

\footnotetext{
${ }^{55}$ http://www.hesonline.nhs.uk/Ease/servlet/ContentServer?siteID=1937\&categoryID=537 (accessed 4
} July 2006). 


\section{Appendix C. Calculation of estimates of costs of a life year saved}

Estimates of the cost per life year saved by increasing nurses' wages (by increasing the inside wage) and increasing the shares of skilled labor are as follows.

We use the GMM estimates of Table 2 (column 3) and Table 4 (column 3), mean AMI death rates (mean death rate $=21 \%$, mean AMI admissions $=385$ ) and staff numbers (total staff $=1700$, mean nurses $=1006$ ) from our data, and mean wages for $1999^{56}$.

The reduction in fatalities and the costs are:

- A $10 \%$ increase in inside wages decreases death rate by $3.71 \%$. New death rate $=20.23 \%$. Decrease in deaths $=(385 * 0.0077)=3$. Cost $=(£ 1,006 * 10 \% * £ 15,000)=£ 1.5 \mathrm{~m}$.

- A one-percentage point increase in the share of nurses reduces AMI death rate by $1.4 \%$. Death rate fall $=(21 \% * 0.014)=0.294 \%$. Decrease in deaths $=(385 * 0.00294)=1$. A one-percentage point increase in nurses (relative to unskilled) $=17$. Cost $=17 * £(15,000-£ 10,000)=£ 85,000$.

- A one-percentage point increase in share of physicians reduces AMI deaths rates by $2.6 \%$. Decrease in deaths $=2$. Cost $=17 * £(50,000-10000)=£ 680,000$.

To derive an estimate of the cost per life year saved we translate one fatality reduction into life years gained. The modal admission in our data is a male aged 70-74. Life expectancy in 2000 for this agegender group ages was $11.1^{57}$, so each fatality reduction = 11 saved life years. With this assumption the ball park cost of one patient year gained from:

- $\quad$ increasing inside nurse wages $=£ 45,000$

- $\quad$ increasing physician share $=£ 31,000$

- $\quad$ increasing nurse share $=£ 8,000$.

These can be compared with US estimates of the cost per life year of technological innovation. Cutler and McClellan (2001) estimated the cost of a one year increase in life expectancy after a heart attack was around \$10,000 between 1984 and 1998, which Heidenreich and McClellan (2001) attribute to the use of low cost treatments such as aspirin, beta-blockers, and thrombolytics. Skinner et al (2006) derive a cost per life year saved of just under $\$ 300,000$ for the period since 1996 . Note our back of the envelope estimates are a lower bound as they incorporate only the impact of preventing AMI fatalities and do not include any effect on productivity and the use of expensive agency staff.

\footnotetext{
${ }^{56}$ Staff numbers from Table 1 . Wages: $£ 15,000$ p.a. for a qualified nurse, $£ 10,000$ for a health assistant and $£ 50,000$ for a physician (http://www.dh.gov.uk/en/Publicationsandstatistics/Pressreleases/DH_4002451).

${ }^{57}$ Government Actuary calculations for England for 1999-2001 http://www.gad.gov.uk/Life_Tables/docs/whltengm.xls
} 


\section{Additional References}

Aiken, Linda H., Sean P. Clarke, Douglas M. Sloane, Julie Sochalski, and Jeffrey H. Silber. 2002 "Hospital Nurse Staffing and Patient Mortality, Nurse Burnout and Job Dissatisfaction.” Journal of the American Medical Association 288 (October 23): 1987-1993.

Askildsen, Jan Erik, Badi H. Baltagi, and Tor H. Holmas. 2002. "Will increased wages reduce shortages of nurses? A panel data study of nurse labor supply." Working Paper in Economics no 21-2002, Department of Economics, University of Bergen.

Bartel, Ann, Beaulieu, Nancy, Phibbs, Ciaran S, Stone, Patricia. 2007. Human Capital and Relational Capital in the Nursing Workforce: An Analysis of their Impacts on Patient Outcomes, mimeo, Columbia Business School

Buerhaus, Peter, Staiger, Douglas, David Auerbach. 2004. "New signs of a strengthening US Nurse Labor Market?” Health Affairs w4:526-533.

Curtin, Leah L. 2003 "An Integrated Analysis of Nurse Staffing and Related Variables: Effects on Patient Outcomes.” Online Journal of Issues in Nursing 8 (September): www.nursingworld.org/ojin/topic22/tpc22_5.htm.

Elliott, Robert F., Ada H. Y. Ma, Anthony Scott, David Bell, and Elizabeth Roberts. 2007. "Geographically differentiated pay in the labor market for nurses." Journal of Health Economics 26 (January): 191-212.

Holmas, Tor H. 2002. "Keeping nurses at work: a duration analysis”. Health Economics 11: 493-503.

Jensen, Gail A., and Michael A. Morrisey. 1986. “The Role of Physicians in Hospital Production.” The Review of Economics and Statistics 68 (May): 432-442.

Mark, Barbara A., David W. Harless, Michael McCue, and Yihua Xu. 2004 “A Longitudinal Examination of Hospital Registered Nurse Staffing and Quality of Care.” Health Services Research 39 (April): 279-300.

McClellan, Mark, and Doug Staiger. 2000. "Comparing the Quality of Health Care Providers.” In Frontiers in Health Policy Research, Volume 3, edited by Alan M. Garber. Cambridge, MA: MIT Press.

Needleman, Jack, Peter Buerhaus, Soeren Mattke, Maureen Stewart, and Katya Zelevinsky. 2002. "Nurse-Staffing Levels and the Quality of Care in Hospitals.” New England Journal of Medicine 346 (May 30): 1715-1722.

Skatun, Diane, Emanuela Antonazzo, Anthony Scott, and Robert F. Elliott. 2005. "The supply of qualified nurses: a classical model of labor supply." Applied Economics 37 (1): 57-65. 
Table A1: Data sources

\begin{tabular}{|c|c|c|}
\hline & Source of Data & Years \\
\hline $\begin{array}{l}\text { AMI deaths and admissions } \\
\text { rates }\end{array}$ & Hospital Episode Statistics (HES) & $1995-2002$ \\
\hline $\begin{array}{l}\text { Finished Consultant Episodes } \\
\text { (FCEs) }\end{array}$ & HES & 1995-2002 \\
\hline AMI case mix & $\begin{array}{l}\text { HES; HRG codes E11 (AMI w/ } \\
\text { complications) and E12 (AMI w/o } \\
\text { complications) }\end{array}$ & 1996-2002 \\
\hline FCE case mix & $\begin{array}{l}\text { HES; index based on HRGs and } \\
\text { national reference costs }\end{array}$ & $1995-2001$ \\
\hline $\begin{array}{l}\text { Whole time equivalents of } \\
\text { clinical staff (Physicians, } \\
\text { Qualified Nurses Unqualified } \\
\text { Nurses; Qualified AHPs; } \\
\text { Unqualified AHPs; Health } \\
\text { Care Assistants) }\end{array}$ & $\begin{array}{l}\text { Department of Health Medical } \\
\text { Workforce Census }\end{array}$ & 1995-2002 \\
\hline $\begin{array}{l}\text { Expenditure on agency nurses } \\
\text { (and all other clinical staff } \\
\text { groups) }\end{array}$ & $\begin{array}{l}\text { Trust financial returns (from Dept } \\
\text { Health) }\end{array}$ & 1995-2002 \\
\hline Nurse vacancy rates & Office of Manpower Economics & 1996-2001 \\
\hline $\begin{array}{l}\text { Local authority directly } \\
\text { standardized all cause } \\
\text { mortality rates and AMI rates }\end{array}$ & Office of National Statistics & $1995-2004$ \\
\hline $\begin{array}{l}\text { Outside wage data (regional } \\
\text { and area wages) }\end{array}$ & New Earnings Survey & $1995-2001$ \\
\hline MRSA rates & $\begin{array}{l}\text { Health Protection Agency } \\
\text { Communicable Disease } \\
\text { Surveillance Centre }\end{array}$ & 2001-2002 \\
\hline Ambulance times & $\begin{array}{l}\text { Department of Health, Health Care } \\
\text { Statistics }\end{array}$ & 1998-2002 \\
\hline $\begin{array}{l}\text { Trust retained surplus and } \\
\text { deficits }\end{array}$ & $\begin{array}{l}\text { Trust financial returns TAC01 } \\
\text { (from Department of Health) }\end{array}$ & 1997-2002 \\
\hline NPRB IV wage & $\begin{array}{l}\text { Gosling and Van Reenen (2005) } \\
\text { predicted regional wage based on } \\
\text { National Pay Review Body } \\
\text { recommendation. }\end{array}$ & 1984-2001 \\
\hline
\end{tabular}

Notes: Both NES and NHS years are financial years commencing in April of each calendar year. ONS data are for calendar years. 
Table A2: AMI admissions and in-hospital death rates in 1997/98, over 55s only

\begin{tabular}{|c|c|c|c|c|}
\hline \multirow[b]{2}{*}{ Time until death } & \multicolumn{2}{|c|}{ Primary diagnosis } & \multicolumn{2}{|c|}{ Primary or secondary diagnosis } \\
\hline & Frequency & Percent of total & Frequency & Percent of total \\
\hline 0 days & 3,220 & 26 & 3,647 & 25 \\
\hline 1 day & 2,780 & 22 & 3,213 & 22 \\
\hline 2 days & 1,424 & 11 & 1,683 & 11 \\
\hline 3 to 5 days & 2,111 & 17 & 2,511 & 17 \\
\hline 6 to 10 days & 1,456 & 12 & 1,811 & 12 \\
\hline 11 to 20 days & 914 & 7 & 1,197 & 8 \\
\hline 21 to 30 days & 251 & 2 & 336 & 2 \\
\hline More than 30 days & 276 & 2 & 362 & 2 \\
\hline Total known & 12,432 & 100 & 14,760 & 100 \\
\hline Unknown & 1 & & 1 & \\
\hline Total & 12,433 & & 14,761 & \\
\hline
\end{tabular}

Source: Authors calculations from HES data. 
Table A3: Example of nursing pay bands, $1^{\text {st }}$ April 1999

(a) Basic Pay Scales

\begin{tabular}{|c|c|c|c|}
\hline Clinical Grade & Description, example & Minimum Epa & Spine points \\
\hline A & Nursing Auxiliary & $\begin{array}{l}£ 7,955(<18) \\
£ 8,705(18+)\end{array}$ & 3 to 9 \\
\hline B & $\begin{array}{l}\text { Nursing Auxiliary } \\
\text { working without } \\
\text { supervision }\end{array}$ & $£ 10,310$ & 8 to 12 \\
\hline C & Enrolled nurse & $£ 11,735$ & 12 to 17 \\
\hline $\mathrm{D}$ & $\begin{array}{l}\text { Staff nurse without } \\
\text { further qualifications }\end{array}$ & $£ 14,400$ & 18 to 21 \\
\hline $\mathrm{E}$ & $\begin{array}{l}\text { Staff nurse with } \\
\text { qualifications }\end{array}$ & $£ 15,395$ & 20 to 24 \\
\hline $\mathrm{F}$ & Ward sister & $£ 17,075$ & 23 to 28 \\
\hline G & $\begin{array}{l}\text { Ward sister with } \\
\text { additional ward } \\
\text { experience, district nurse, } \\
\text { health visitor, community } \\
\text { midwife }\end{array}$ & $£ 20,145$ & 27 to 31 \\
\hline $\mathrm{H}$ & $\begin{array}{l}\text { Senior nurse with } \\
\text { responsibility for } \\
\text { management of more than } \\
\text { one ward }\end{array}$ & $£ 22,505$ & 30 to 34 \\
\hline I & $\begin{array}{l}\text { Senior nurse with } \\
\text { management } \\
\text { responsibility and } \\
\text { teaching qualifications }\end{array}$ & $£ 24,920$ & 33 to 37 \\
\hline
\end{tabular}

(b) Local Allowances

\begin{tabular}{|c|c|c|c|}
\hline Clinical Grade & Inner London & Outer London & Fringe \\
\hline $\mathrm{A}$ and $\mathrm{B}$ & $\begin{array}{l}£ 1850+5 \% \text { of salary up } \\
\text { to a maximum of } £ 750\end{array}$ & $\begin{array}{l}£ 1570+5 \% \text { of salary } \\
\text { up to a maximum of } \\
£ 750\end{array}$ & $\begin{array}{l}£ 285+2.5 \% \\
\text { of salary up to } \\
\text { a maximum of } \\
£ 375\end{array}$ \\
\hline $\mathrm{C}$ and above & $\begin{array}{l}£ 2205+5 \% \text { of salary up } \\
\text { to a maximum of } £ 750\end{array}$ & $\begin{array}{l}£ 1570+5 \% \text { of salary } \\
\text { up to a maximum of } \\
£ 750\end{array}$ & $\begin{array}{l}£ 285+2.5 \% \\
\text { of salary up to } \\
\text { a maximum of } \\
£ 375\end{array}$ \\
\hline
\end{tabular}

Source: Income Data Services (2000) Pay in the Public Services: Review of 1999, prospects for 2000. One UK $£$ is approximately two US\$. 
Table A4: Productivity Regressions for service industries, 1996-2001, coefficient (standard error) on area outside wage

\begin{tabular}{|c|c|c|c|c|c|}
\hline $\begin{array}{l}\text { Dependent variable: } \\
\text { Industry Name }\end{array}$ & $\begin{array}{l}\text { Ln(Sales per worker) } \\
\text { US SIC Code (1987) }\end{array}$ & $\begin{array}{l}\text { OLS } \\
(1) \\
\end{array}$ & $\begin{array}{l}3 \text { year annual Long } \\
\text { Differences } \\
(2)\end{array}$ & $\begin{array}{l}\text { GMM-SYS } \\
(3) \\
\end{array}$ & $\begin{array}{l}\text { Number of Firms } \\
(4)\end{array}$ \\
\hline Department Stores & 531 & $\begin{array}{l}0.021 \\
(0.042)\end{array}$ & $\begin{array}{l}-0.038 \\
(0.623)\end{array}$ & $\begin{array}{l}-0.253 \\
(0.434)\end{array}$ & 501 \\
\hline Grocery Stores & 541 & $\begin{array}{l}-0.587 \\
(0.936)\end{array}$ & $\begin{array}{l}-0.004 \\
(1.730)\end{array}$ & $\begin{array}{l}0.375 \\
(1.307)\end{array}$ & 219 \\
\hline $\begin{array}{l}\text { Meat and Fish } \\
\text { Markets }\end{array}$ & 542 & $\begin{array}{l}-1.022 \\
(1.032)\end{array}$ & $\begin{array}{l}-7.916 * * * \\
(1.546)\end{array}$ & $\begin{array}{l}-0.379 \\
(1.148)\end{array}$ & 71 \\
\hline Confectionery Stores & 544 & $\begin{array}{l}2.257 \\
(3.832)\end{array}$ & $\begin{array}{l}5.975 \\
(5.717)\end{array}$ & $\begin{array}{l}-0.927 \\
(1.207)\end{array}$ & 48 \\
\hline $\begin{array}{l}\text { Miscellaneous Food } \\
\text { Stores }\end{array}$ & 549 & $\begin{array}{l}-0.663 \\
(2.170)\end{array}$ & $\begin{array}{l}-1.356 \\
(4.595)\end{array}$ & $\begin{array}{l}-0.397 \\
(1.272)\end{array}$ & 58 \\
\hline $\begin{array}{l}\text { Gasoline Service } \\
\text { Stations }\end{array}$ & 554 & $\begin{array}{l}1.458 \\
(2.118)\end{array}$ & $\begin{array}{l}3.472 \\
(1.991)\end{array}$ & $\begin{array}{l}1.052 \\
(1.806)\end{array}$ & 179 \\
\hline Motorcycle Dealers & 557 & $\begin{array}{l}-5.733^{* *} \\
(2.574)\end{array}$ & $\begin{array}{l}1.639 * * * \\
(0.415)\end{array}$ & $\begin{array}{l}-1.684^{*} \\
(1.017)\end{array}$ & 32 \\
\hline $\begin{array}{l}\text { Family Clothing } \\
\text { Stores }\end{array}$ & 565 & $\begin{array}{l}0.458 \\
(0.442)\end{array}$ & $\begin{array}{l}-0.649 \\
(1.261)\end{array}$ & $\begin{array}{l}0.147 \\
(0.400)\end{array}$ & 490 \\
\hline Shoe Stores & 566 & $\begin{array}{l}-3.133^{* * *} \\
(1.189)\end{array}$ & $\begin{array}{l}0.758 \\
(4.093)\end{array}$ & $\begin{array}{l}-1.801^{* *} \\
(0.794)\end{array}$ & 122 \\
\hline $\begin{array}{l}\text { Home furnishing } \\
\text { Stores }\end{array}$ & 571 & $\begin{array}{l}1.650 * * * \\
(0.629)\end{array}$ & $\begin{array}{l}0.484 \\
(1.021)\end{array}$ & $\begin{array}{l}0.899 \\
(0.609)\end{array}$ & 275 \\
\hline $\begin{array}{l}\text { Household Appliance } \\
\text { Stores }\end{array}$ & 572 & $\begin{array}{l}1.576^{*} \\
(0.811)\end{array}$ & $\begin{array}{l}0.050 \\
(1.578)\end{array}$ & $\begin{array}{l}1.681^{* *} \\
(0.730)\end{array}$ & 224 \\
\hline
\end{tabular}




\begin{tabular}{|c|c|c|c|c|c|}
\hline Eating and Drinking & 581 & $0.817 * *$ & 0.368 & 0.152 & 1546 \\
\hline Places & & $(0.377)$ & $(0.742)$ & $(0.351)$ & \\
\hline Drug Stores and & 591 & 0.273 & -1.725 & 0.044 & 223 \\
\hline Proprietary Stores & & $(0.577)$ & $(1.870)$ & $(0.609)$ & \\
\hline Liquor Stores & 592 & $\begin{array}{l}1.619 \\
(1.873)\end{array}$ & $\begin{array}{l}-0.964 \\
(2.297)\end{array}$ & $\begin{array}{l}0.433 \\
(1.321)\end{array}$ & 71 \\
\hline $\begin{array}{l}\text { Used Merchandise } \\
\text { Stores }\end{array}$ & 593 & $\begin{array}{l}0.664 \\
(1.121)\end{array}$ & $\begin{array}{l}-2.359 \\
(9.258)\end{array}$ & $\begin{array}{l}0.502 \\
(1.163)\end{array}$ & 146 \\
\hline Jewelry Stores & 594 & $\begin{array}{l}-0.020 \\
(0.909)\end{array}$ & $\begin{array}{l}-1.437 \\
(1.987)\end{array}$ & $\begin{array}{l}0.396 \\
(0.955)\end{array}$ & 155 \\
\hline $\begin{array}{l}\text { Catalog, Mail-Order } \\
\text { Houses and direct } \\
\text { selling outlets }\end{array}$ & 596 & $\begin{array}{l}0.423 \\
(1.006)\end{array}$ & $\begin{array}{l}3.484 \\
(2.307)\end{array}$ & $\begin{array}{l}0.186 \\
(1.013)\end{array}$ & 246 \\
\hline $\begin{array}{l}\text { Miscellaneous Retail } \\
\text { Stores }\end{array}$ & 599 & $\begin{array}{l}0.589 \\
(0.585)\end{array}$ & $\begin{array}{l}1.107 \\
(1.110)\end{array}$ & $\begin{array}{l}0.382 \\
(0.424)\end{array}$ & 711 \\
\hline Hotels and Motels & 701 & $\begin{array}{l}0.548^{* *} \\
(0.268)\end{array}$ & $\begin{array}{l}1.393^{* * *} \\
(0.437)\end{array}$ & $\begin{array}{l}0.184 \\
(0.225)\end{array}$ & 1098 \\
\hline $\begin{array}{l}\text { Rooming and } \\
\text { Boarding Houses }\end{array}$ & 702 & $\begin{array}{l}-1.009 \\
(0.879)\end{array}$ & $\begin{array}{l}-5.308 \\
(4.305)\end{array}$ & $\begin{array}{l}-0.444 \\
(0.921)\end{array}$ & 102 \\
\hline $\begin{array}{l}\text { Sporting, } \\
\text { Recreational Camps }\end{array}$ & 703 & $\begin{array}{l}1.373 * * \\
(0.596)\end{array}$ & $\begin{array}{l}-0.276 \\
(0.670)\end{array}$ & $\begin{array}{l}0.642 \\
(0.501)\end{array}$ & 88 \\
\hline $\begin{array}{l}\text { Laundry and Garment } \\
\text { Services }\end{array}$ & 721 & $\begin{array}{l}0.228 \\
(0.267)\end{array}$ & $\begin{array}{l}-0.543 \\
(0.542)\end{array}$ & $\begin{array}{l}0.057 \\
(0.222)\end{array}$ & 3577 \\
\hline $\begin{array}{l}\text { Photographic Studios, } \\
\text { Portrait }\end{array}$ & 722 & $\begin{array}{l}-0.994 \\
(0.754)\end{array}$ & $\begin{array}{l}-2.153 \\
(2.436)\end{array}$ & $\begin{array}{l}-0.330 \\
(1.099)\end{array}$ & 138 \\
\hline Beauty Shops & 723 & $\begin{array}{l}-2.053^{* *} \\
(0.826)\end{array}$ & $\begin{array}{l}3.315 \\
(10.585)\end{array}$ & $\begin{array}{l}-1.081 \\
(0.901)\end{array}$ & 126 \\
\hline $\begin{array}{l}\text { Funeral Services and } \\
\text { Crematories }\end{array}$ & 726 & $\begin{array}{l}1.390^{*} \\
(0.779)\end{array}$ & $\begin{array}{l}0.555 \\
(2.225)\end{array}$ & $\begin{array}{l}1.520 \\
(0.883)\end{array}$ & 166 \\
\hline Miscellaneous & 729 & 1.283 & $-3.885 * * *$ & 0.493 & 46 \\
\hline
\end{tabular}




\begin{tabular}{|c|c|c|c|c|c|}
\hline \multirow{2}{*}{$\begin{array}{l}\text { Personal Services, } \\
\text { Advertising }\end{array}$} & & (1.159) & $(1.013)$ & $(1.046)$ & \\
\hline & 731 & $\begin{array}{l}-1.004 * \\
(0.526)\end{array}$ & $\begin{array}{l}0.283 \\
(0.944)\end{array}$ & $\begin{array}{l}-0.218 \\
(0.637)\end{array}$ & 809 \\
\hline Building Cleaning & 734 & $\begin{array}{l}0.522 \\
(0.495)\end{array}$ & $\begin{array}{l}1.797 \\
(1.231)\end{array}$ & $\begin{array}{l}0.815 \\
(0.371)\end{array}$ & 215 \\
\hline Industrial Rental & 735 & $\begin{array}{l}-0.370 \\
(0.483)\end{array}$ & $\begin{array}{l}0.558 \\
(0.960)\end{array}$ & $\begin{array}{l}-0.091 \\
(0.437)\end{array}$ & 441 \\
\hline $\begin{array}{l}\text { Employment } \\
\text { Agencies }\end{array}$ & 736 & $\begin{array}{l}-0.005 \\
(0.561)\end{array}$ & $\begin{array}{l}0.289 \\
(1.032)\end{array}$ & $\begin{array}{l}-0.474 \\
(0.503)\end{array}$ & 371 \\
\hline Computer services & 737 & $\begin{array}{l}0.277 \\
(0.191)\end{array}$ & $\begin{array}{l}0.304 \\
(0.433)\end{array}$ & $\begin{array}{l}0.119 \\
(0.180)\end{array}$ & 6151 \\
\hline $\begin{array}{l}\text { Misc. Business } \\
\text { Services (security, } \\
\text { news, photofinishing } \\
\text { etc.) }\end{array}$ & 738 & $\begin{array}{l}0.396^{*} \\
(0.220)\end{array}$ & $\begin{array}{l}-0.195 \\
(0.544)\end{array}$ & $\begin{array}{l}0.438^{* *} \\
(0.199)\end{array}$ & 7117 \\
\hline Car Rental & 751 & $\begin{array}{l}0.827 \\
(1.217)\end{array}$ & $\begin{array}{l}1.156 \\
(1.262)\end{array}$ & $\begin{array}{l}0.892 \\
(1.190)\end{array}$ & 180 \\
\hline Auto repair shops & 753 & $\begin{array}{l}-0.161 \\
(0.618)\end{array}$ & $\begin{array}{l}0.954 \\
(0.796)\end{array}$ & $\begin{array}{l}0.056 \\
(0.493)\end{array}$ & 492 \\
\hline Non-auto repair shops & 769 & $\begin{array}{l}3.696 \\
(2.965)\end{array}$ & $\begin{array}{l}-5.646 \\
(6.739)\end{array}$ & $\begin{array}{l}-3.751 \\
(2.452)\end{array}$ & 58 \\
\hline $\begin{array}{l}\text { Movie production } \\
\text { services }\end{array}$ & 781 & $\begin{array}{l}-1.824^{*} \\
(0.953)\end{array}$ & $\begin{array}{l}10.427 \\
(10.102)\end{array}$ & $\begin{array}{l}2.343 * * \\
(0.994)\end{array}$ & 139 \\
\hline $\begin{array}{l}\text { Movie distribution } \\
\text { services }\end{array}$ & 782 & $\begin{array}{l}-7.044 \\
(5.509)\end{array}$ & $\begin{array}{l}-26.706 \\
(16.205)\end{array}$ & $\begin{array}{l}-2.057 \\
(2.816)\end{array}$ & 67 \\
\hline Dance Studios & 791 & $\begin{array}{l}0.716 \\
(0.950)\end{array}$ & $\begin{array}{l}-4.476^{* * * *} \\
(1.520)\end{array}$ & $\begin{array}{l}0.434 \\
(0.685)\end{array}$ & 709 \\
\hline $\begin{array}{l}\text { Theatrical Producers } \\
\text { and Services (Except } \\
\text { Movies) }\end{array}$ & 792 & $\begin{array}{l}-0.168 \\
(1.149)\end{array}$ & $\begin{array}{l}5.480 * * \\
(2.168)\end{array}$ & $\begin{array}{l}1.493 \\
(1.418)\end{array}$ & 216 \\
\hline
\end{tabular}




\begin{tabular}{llllll}
$\begin{array}{l}\text { Professional Sports } \\
\text { Clubs, racing and }\end{array}$ & 794 & $1.053^{* *}$ & 0.363 & $0.817^{* *}$ & 700 \\
$\begin{array}{l}\text { Promoters } \\
\text { Gyms and other }\end{array}$ & & $(0.419)$ & $(0.537)$ & $(0.385)$ & \\
sports recreation & 799 & 1.051 & -0.562 & 0.495 & 528 \\
Legal Services & \multirow{2}{*}{811} & $(0.804)$ & $(0.891)$ & $(0.652)$ & 100 \\
& & -0.095 & 2.314 & 0.676 & $(0.924)$ \\
\hline
\end{tabular}

Notes: These specifications are analogous to those in Table 3. The coefficient (standard error) is that on the $\ln ($ outside wage) variable which is identical to that of Table 3 (and elsewhere). We use company level panel data from UK part of AMADEUS data (all firms in UK economy with non-missing data on variables) between 1996 and 2001. We selected three digit industries in two digit codes from US SIC (1987) 53 through 60 and 71 through 81 (the main service industries in the private sector where women work). Only regressions with at least 100 observations were included (which is why some three-digit sectors where not used). Controls include ln(inside wage),

$\ln ($ capital/labor ratio), $\ln ($ employees), 10 regional dummies and time dummies. Column (1) estimated by OLS. Long-differences are three- year annual average growth rates in column (2). In the System-GMM estimates of column (3), one-step robust estimates are presented. Capital, employment and inside wages are treated as endogenous (the outside wage is lagged and treated as exogenous). In the GMM specification instruments in the differenced equations are levels of own values t-2 through t-5; instruments in the levels equations are once lagged differences. Standard errors in parentheses under coefficients are robust to arbitrary heteroskedacity and autocorrelation. 